EUROPEAN CENTRAL BANK

WORKING PAPER SERIES

NO. 3 I 9 / MARCH 2004

\title{
RISK SHARING \\ THROUGH \\ FINANCIAL \\ MARKETS WITH \\ ENDOGENOUS \\ ENFORCEMENT \\ OF TRADES
}

by Thorsten V. Köppl

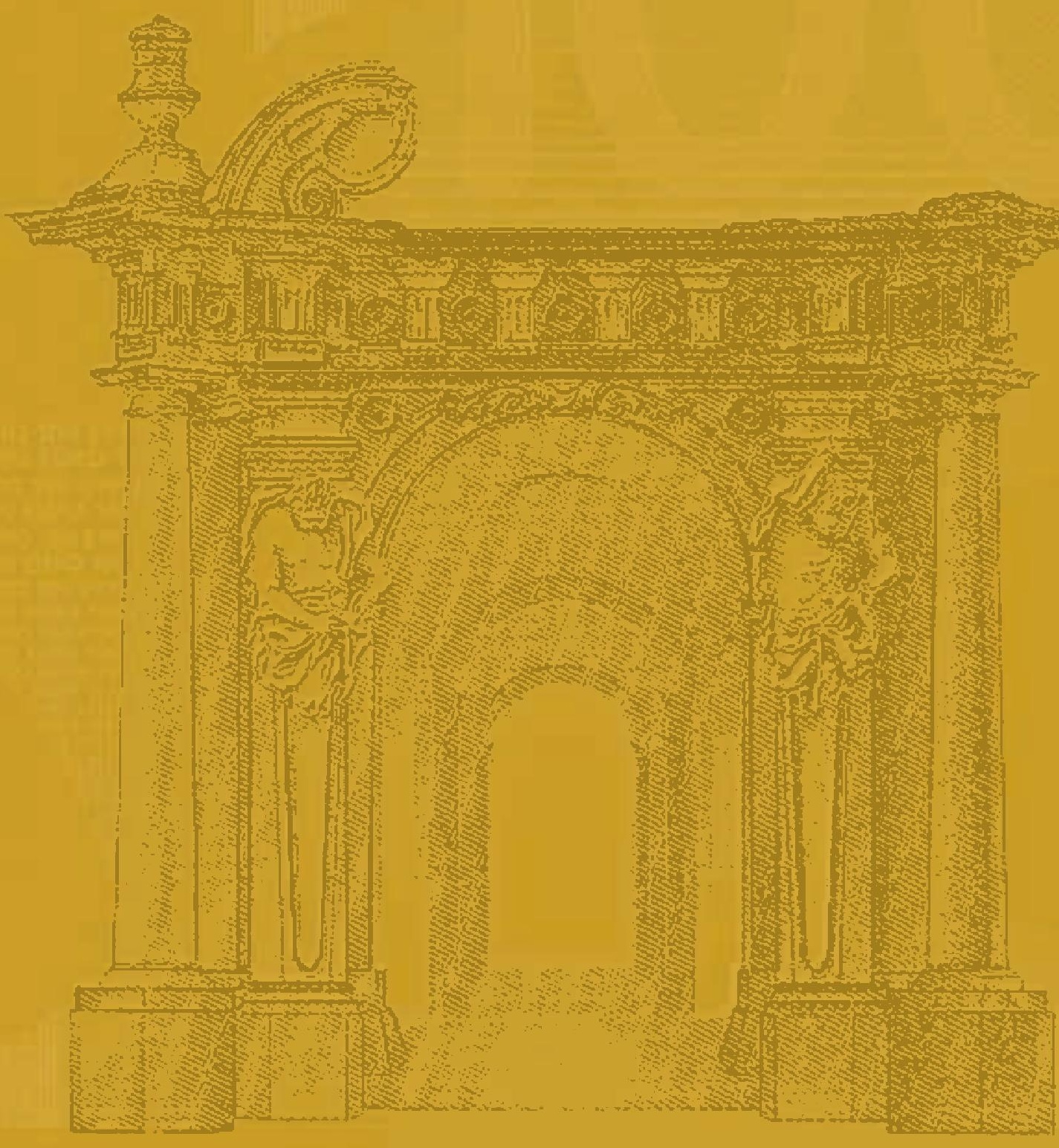


RISK SHARING THROUGH FINANCIAL MARKETS WITH ENDOGENOUS ENFORCEMENT OF TRADES

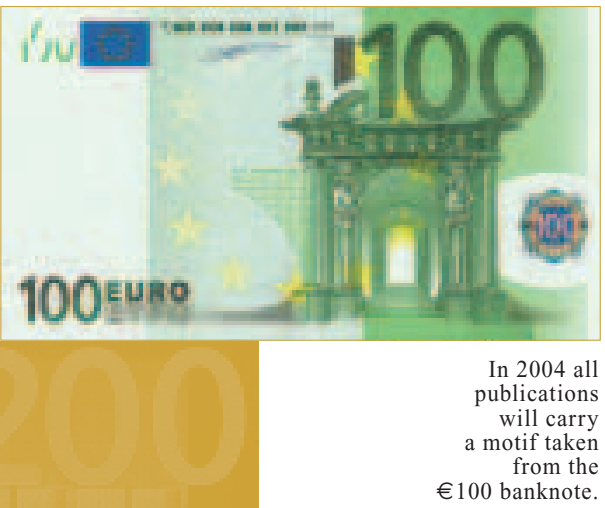

by Thorsten V. Köppl ${ }^{2}$

This paper can be downloaded without charge from http://www.ecb.int or from the Social Science Research Network electronic library at http://ssrn.com/abstract_id $=532942$.

I I would like to thank Beth Allen, Narayana Kocherlakota and Jan Werner for their encouragement and discussions while working on the subject. I gratefully acknowledge comments by seminar participants at the Universities of Minnesota, Bielefeld, Nova, Western Ontario, Queen's, at the 2003 SED meetings in Paris, the SAET conference in Rhodes, the JEDC conference "Contracts and Institutions" 2003 in Frankfurt and the North American Winter Meetings of the Econometric Society 2004 in San Diego.

Support was provided through theWalter H. Heller Memorial Dissertation Fellowship and the hospitality of the Federal Reserve Bank of Minneapolis where part of this research was undertaken. The views expressed here are those of the author and do not necessarily reflect those of the ECB, the Federal 


\section{드 European Central Bank, 2004}

\section{Address}

Kaiserstrasse 29

60311 Frankfurt am Main, Germany

Postal address

Postfach 160319

60066 Frankfurt am Main, Germany

Telephone

+496913440

\section{Internet}

http://www.ecb.int

Fax

+496913446000

Telex

411144 ecb d

All rights reserved.

Reproduction for educational and noncommercial purposes is permitted provided that the source is acknowledged.

The views expressed in this paper do not necessarily reflect those of the European Central Bank.

The statement of purpose for the ECB Working Paper Series is available from the ECB website, http://www.ecb.int.

ISSN 1561-0810 (print)

ISSN 1725-2806 (online) 


\section{CONTENTS}

Abstract 4

Non-technical summary 5

1 Introduction 7

2 Environment 10

2.1 Physical environment $\quad 10$

2.2 Incentive feasible allocation $\quad 12$

2.3 Optimal allocations $\quad$ |3

3 Lindahl equilibria with enforcement intermediaries $\quad 15$

3.1 Enforcement intermediaries $\quad \mid 6$

3.2 Asset markets and borrowing constraints

3.3 Lindahl-equilibrium for sequential security markets $\quad \| 9$

3.4 Second welfare theorem 2I

4 Optimality of Lindahl-equilibria 26

5 Asset pricing implications 29

6 Discussion 31

7 Appendix 34

References 45

European Central Bank working paper series 


\begin{abstract}
When people share risk in financial markets, intermediaries provide costly enforcement for most trades and, hence, are an integral part of financial markets' organization. We assess the degree of risk sharing that can be achieved through financial markets when enforcement is based on the threat of exclusion from future trading as well as on costly enforcement intermediaries. Starting from constrained efficient allocations and taking into account the public good character of enforcement we study a Lindahl-equilibrium where people invest in asset portfolios and simultaneously choose to relax their borrowing limits by paying fees to an intermediary who finances the costs of enforcement. We show that financial markets always allow for optimal risk sharing as long as markets are complete, default is prevented in equilibrium and intermediaries provide costly enforcement competitively. In equilibrium, costly enforcement translates into both agent-specific borrowing limits and price schedules that include a separate default premium. Enforcement costs - or, equivalently, default premia - increase borrowing costs, while interest rates per se depend on the change in enforcement over time.
\end{abstract}

Keywords: Limited Commitment, Enforcement Intermediaries, Lindahl-equilibrium, Endogenous Borrowing Constraints

JEL Classifications: C73, D60, G10, H41, K42 


\section{Non-technical Summary}

In modern economies people share risk mainly through trades in financial assets. Most of these trades involve ex-post transfers between the parties involved and have to be enforced since a party obliged to make a transfer has necessarily an incentive to default. To enforce trades many institutions have been set up that assess the problem of default, specify penalties for default and carry out these penalties. One example is a bankruptcy procedure with its specific set of rules, its application through a court system and its enforcement by public authorities. Other examples are enforcement and financial intermediaries such as rating and collection agencies, clearinghouses or settlement banks.

Since these intermediaries provide costly enforcement for most transactions on financial markets, they form an integral part of financial markets' organization. The goal of this paper is first to assess the degree of risk sharing that can be achieved through financial markets when intermediaries provide costly enforcement of trades. We then investigate how default is prevented in equilibrium when intermediaries provide enforcement and agents bear the costs associated with enforcement when making their financial decisions.

The basic set-up for our analysis is a standard dynamic risk sharing problem where commitment to contracts is limited. In our framework however, when enforcing risk sharing people can rely not only on the threat of exclusion from future risk sharing, but also on a punishment technology. While resources are required to operate this technology, it allows for enforcement by inflicting a utility penalty on a person that violates the arrangement. Enforcement is thus treated as a decision variable, since the technology choice forms part of the risk sharing arrangement itself.

After characterizing optimal risk sharing, we establish versions of the Welfare Theorems by introducing a perfectly competitive, profit-maximizing intermediary that operates the punishment technology. Since operating this technology acts as a threat to enforce financial trades, enforcing an obligation of someone does not preclude the use of this technology to enforce obligations of anybody else. Hence, this non-rivalry causes enforcement through the intermediary to be a public good.

To capture these characteristics we use the ideas of Lindahl-equilibrium when decentralizing optimal allocations. We assume that asset markets are complete and people are restricted in their trades by borrowing constraints. Limits on borrowing take the form of "endogenous solvency constraints" that rule out default in equilibrium. Given equilibrium prices people can borrow up to a level of debt that they are willing to pay back. This amount reflects not only that people are excluded from asset markets forever after defaulting, but also punished through the technology.

Individuals, however, do not only choose how much to invest in state-contingent claims subject to a given borrowing limit, but in doing so also decide how restricted they are with respect to their borrowing. In fact, agents can borrow more by "demanding" enforcement to back up larger transactions. Agents therefore choose a borrowing limit from a full schedule of limits associated with different levels of enforcement for a "price" that reflects enforcement costs. As is typical for a Lindahl- 
equilibrium, the intermediary supplies this enforcement competitively by operating the technology on agent-specific markets for individualized prices. Hence, each agent demands the use of the technology on an individualized market facing a price that reflects his marginal utility from enforcement through the technology.

We show that financial markets always allow for optimal risk sharing as long as markets are complete, default is prevented in equilibrium and intermediaries provide enforcement competitively. Furthermore, in equilibrium costly enforcement translates into both borrowing limits and price schedules that differ across people.

The amount people can borrow is restricted in equilibrium by endogenous solvency constraints. As already pointed out these constraints reflect the punishment associated with default: exclusion from future trade on asset markets plus the utility penalty arising from the punishment technology. Moreover, total costs of borrowing are nonlinear and are composed of a price that is linear and a fee that pays for the costs of enforcing the trade. This fee is agent-specific and reflects the severity of the default problem. Hence, we derive a theory of financial markets structure where people are not only restricted in their borrowing, but also borrow at different rates that reflect the premium required to be able to obtain additional funds.

We also indicate that it is possible to disentangle asset prices into a default-free part and a default premium that is associated precisely with the cost of default. Here enforcement costs - or, equivalently, default premia - are increasing borrowing costs, while the risk-free rate per se tends to be lower. This suggest a potential new route for analyzing pricing puzzles by decomposing agent-specific interest rates into components that reflect different sources of costs. Furthermore, we offer a way to incorporate optimal market design into general equilibrium theory. Since the intermediaries offer and people demand enforcement as part of their optimal behavior, one can see a first step towards deriving a theory of how markets set borrowing limits and price claims that are subject to default. 


\section{Introduction}

In modern economies people share risk mainly through trades in financial assets. Most of these trades involve ex-post transfers between the parties involved and have to be enforced since a party obliged to make a transfer has necessarily an incentive to default. To enforce trades many institutions have been set up that assess the problem of default, specify penalties for default and carry out these penalties. One example is a bankruptcy procedure with its specific set of rules, its application through a court system and its enforcement by public authorities. Other examples are enforcement and financial intermediaries such as rating and collection agencies, clearinghouses or settlement banks.

Since these intermediaries provide costly enforcement for most transactions on financial markets, they form an integral part of financial markets' organization. The goal of this paper is first to assess the degree of risk sharing that can be achieved through financial markets when intermediaries provide costly enforcement of trades. We then investigate how default is prevented in equilibrium when intermediaries provide enforcement and agents bear the costs associated with enforcement when making their financial decisions.

The basic set-up for our analysis is a standard dynamic risk sharing problem where commitment to contracts is limited. ${ }^{1}$ In our framework however, when enforcing risk sharing people can rely not only on the threat of exclusion from future risk sharing, but also on a punishment technology. While resources are required to operate this technology, it allows for enforcement by inflicting a utility penalty on a person that violates the arrangement. Enforcement is thus treated as a decision variable, since the technology choice forms part of the risk sharing arrangement itself. ${ }^{2}$

After characterizing optimal risk sharing, we establish versions of the Welfare Theorems by introducing a perfectly competitive, profit-maximizing intermediary that operates the punishment technology. Since operating this technology acts as a threat to enforce

\footnotetext{
${ }^{1}$ Examples of this literature include Coate and Ravallion (1993), Kocherlakota (1996), Ligon et al. (2002) among others.

${ }^{2}$ For a detailed discussion of this approach see Koeppl (2003).
} 
financial trades, enforcing an obligation of someone does not preclude the use of this technology to enforce obligations of anybody else. Hence, this non-rivalry causes enforcement through the intermediary to be a public good. ${ }^{3}$

To capture these characteristics we use the ideas of Lindahl-equilibrium ${ }^{4}$ when decentralizing optimal allocations. We assume that asset markets are complete and people are restricted in their trades by borrowing constraints. Following Alvarez and Jermann (2000) borrowing limits take the form of "endogenous solvency constraints" that rule out default in equilibrium. Given equilibrium prices people can borrow up to a level of debt that they are willing to pay back. This amount reflects not only that people are excluded from asset markets forever after defaulting, but also punished through the technology.

Individuals, however, do not only choose how much to invest in state-contingent claims subject to a given borrowing limit, but in doing so also decide how restricted they are with respect to their borrowing. In fact, agents can borrow more by "demanding" enforcement to back up larger transactions. Agents therefore choose a borrowing limit from a full schedule of limits associated with different levels of enforcement for a "price" that reflects enforcement costs. As is typical for a Lindahl-equilibrium, the intermediary supplies this enforcement competitively by operating the technology on agent-specific markets for individualized prices. Hence, each agent demands the use of the technology on an individualized market facing a price that reflects his marginal utility from enforcement through the technology.

\footnotetext{
${ }^{3}$ Green (2000) emphasizes this feature by pointing out that "Certainty of settlement is a public good in a market where the ability of one trader to meet commitments often depends benefiting from the fulfilment of others' commitments. ... a clearinghouse may set, monitor, and enforce standards of creditworthiness ... it may require participants to transfer securities and funds to one another in reliance on its judgement, rather than exercising their independent judgement of the creditworthiness of counterparties. The clearinghouse may set and compute participants' margin requirements, hold participants' collateral in escrow, ... , manage the liquidation of defaulting participants' positions, and so forth." (Green (2000), p. 23).

${ }^{4}$ For an extensive review on general equilibrium theory with public goods and the concept of Lindahlequilibrium, see Milleron (1972).
} 
We show that financial markets always allow for optimal risk sharing as long as markets are complete, default is prevented in equilibrium and intermediaries provide enforcement competitively. Furthermore, in equilibrium costly enforcement translates into both borrowing limits and price schedules that differ across people.

The amount people can borrow is restricted in equilibrium by endogenous solvency constraints. As already pointed out these constraints reflect the punishment associated with default: exclusion from future trade on asset markets plus the utility penalty arising from the punishment technology. Moreover, total costs of borrowing are non-linear and are composed of a price that is linear and a fee that pays for the costs of enforcing the trade. This fee is agent-specific and reflects the severity of the default problem. Hence, we derive a theory of financial markets structure where people are not only restricted in their borrowing, but also borrow at different rates that reflect the premium required to be able to obtain additional funds.

There is a rich literature that analyzes constraints on debts ${ }^{5}$ while other contributions focus on the importance of various transaction costs for asset prices ${ }^{6}$. We contribute to this large literature by linking debt constraints to the problem of incurring additional costs when enforcing "tighter" constraints. While our findings show how these costs feed into asset prices, we also indicate that it is possible to disentangle asset prices into a default-free part and a default premium that is associated precisely with the cost of default. Here enforcement costs - or, equivalently, default premia - are increasing borrowing costs, while the risk-free rate per se tends to be lower. This suggest a potential new route for analyzing pricing puzzles by decomposing agent-specific interest rates into components that reflect different sources of costs.

Furthermore, we offer a way to incorporate optimal market design into general equilibrium theory. Since the intermediaries offer and people demand enforcement as part of

\footnotetext{
${ }^{5}$ Examples are Levine and Zame (1996), Constantinides and Duffie (1996) and Zhang (1997) among others.

${ }^{6}$ See e.g. Luttmer (1996) and He and Modest (1995).
} 
their optimal behavior, one can see a first step towards deriving a theory of how markets set borrowing limits and price claims that are subject to default. ${ }^{7}$ Finally, even though we analyze enforcement and, hence, a particular public good, an additional contribution of our work here is that we show how to extend the ideas of a Lindahl-equilibrium with individualized markets for a public good to financial markets as well as dynamic environments with sequential market structures where externalities influence only the feasible sets of individual agents.

The remainder of this paper is organized as follows. The next section sets out the framework for our analysis and describes optimal risk sharing with costly third-party enforcement. In Section 3 and 4 we establish different versions of the Second Welfare Theorem incorporating the ideas of enforcement as a public good. Section 5 shows that given our assumptions - financial markets are generally efficient in providing risk sharing even if enforcement is costly to provide. Finally, we discuss asset pricing implications in more detail. All proofs are relegated to the appendix.

\section{Environment}

\subsection{Physical Environment}

Consider the following environment where time is discrete and indexed by $t=0,1, \ldots$ There is a finite set of infinitely lived agents $I$, who receive each period a stochastic endowment of a single good. Let $\omega=\left\{\omega_{1}, \omega_{2}, \ldots\right\}$ be a sequence of independently and identically distributed random variables each having finite support $\Omega=\{1,2, \ldots, S\}$ and denote the probability of $\omega_{t}$ equaling $s$ by $\pi_{s}>0$ for all $s \in \Omega$. Define a $t$-history of $\omega$

\footnotetext{
${ }^{7}$ The literature on consumer bankruptcy has made some progress in this direction (cf. for example Chatterjee, et al. (2002) or Livshits, et al. (2001)). In this literature financial intermediaries when making loans distinguish between agents according to their likelihood of default. Hence, all transactions take place on competitive, but segmented loan markets. This literature, however, does not analyze optimal bankruptcy/enforcement rules and how these rules are implemented on loan markets.
} 
by $\omega^{t}=\left\{\omega_{1}, \omega_{2}, \ldots, \omega_{t}\right\}$ and let $\Omega^{t}$ be the set of all possible $t$-histories of $\omega$ with $\pi\left(\omega^{t}\right)$ being the probability of a particular history. The endowment for agent $i \in I$ in period $t$ is determined by the realization of $\omega_{t}$ and denoted by $y_{t, s}^{i}$ when $\omega_{t}=s$ for $t=0,1, \ldots$ We assume that $y_{t, s}^{i} \neq y_{t, s}^{j}$ for some agents $i, j \in I$ and that $\sum_{i \in I} y_{t, s}^{i}=Y>0$ for all $s \in \Omega$ and $t=0,1, \ldots$, i.e., that there is no aggregate risk and the economy is stationary. This assumption is purely made to facilitate the exposition.

Preferences for agent $i$ are described over $\omega^{t}$-measurable consumption processes $c^{i} \in C=$ $\left\{\left\{c_{t}^{i}\right\}_{t=0}^{\infty} \mid c_{t}^{i}: \Omega^{t} \longrightarrow[0, Y]\right\}$ and represented by the utility function

$$
E_{t}\left[\sum_{\tau=0}^{\infty} \beta^{\tau} u_{i}\left(c_{t+\tau}^{i}\right)\right]
$$

where $\beta \in(0,1)$ and $E_{t}$ expresses the expectation conditional on a history of shocks at time $t$. We assume that $u_{i}$ is increasing, strictly concave and twice continuously differentiable. Furthermore, $u^{i}$ is bounded from below with normalization $u_{i}(0)=0$ and $\lim _{c \rightarrow 0} u_{i}^{\prime}(c)=\infty$.

Since the agents are risk averse and face idiosyncratic income shocks, there is an incentive to share income risk. We assume, however, that there is limited enforcement. Each period, after uncertainty in period $t$ is resolved and the current distribution of endowment $\left\{y_{t, s}^{i}\right\}_{i \in I}$ is known, an agent $i$ can choose to remain in autarky forever. The utility of autarky is given by

$$
u_{i}\left(y_{t, s}^{i}\right)+E_{t}\left[\sum_{\tau=1}^{\infty} \beta^{\tau} u_{i}\left(y_{t+\tau}^{i}\right)\right] \equiv u_{i}\left(y_{t, s}^{i}\right)+\beta V_{a u t}^{i}
$$

where $V_{a u t}^{i}$ expresses the future expected utility from autarky which is independent of the realized history of shocks.

The economy has access to a "punishment" technology that reduces an agent's current and future utility in case this agent decides to remain in autarky. Specifically, if this technology is operated at a level $d_{t} \in[0,1]$ and an agent decides to remain in autarky 
forever in period $t$, the agent loses a fraction $d_{t}$ of her autarkic utility as given by equation $(2)$.

Operating this technology in period $t$ at a level $d_{t}$ requires an investment of resources equal to $\psi\left(d_{t}\right)$ in period $t$ which depreciates fully after one period. The level of this punishment technology in any period $t, d_{t}$, is set before the current shock $\omega_{t}$ is realized. Therefore, the level of punishment in period $t$ can depend only on the past history of realizations of $\omega$, i.e., $\omega^{t-1}$. Formally and slightly abusing notation, we denote the $\omega^{t-1}$ measurable process of punishment levels by $d \in D=\left\{\left\{d_{t}\right\}_{t=0}^{\infty} \mid d_{t}: \Omega^{t-1} \longrightarrow[0,1]\right\}$, where $\Omega^{-1}$ is defined to contain a single element. To ensure the convexity of the problem we assume that the cost function $\psi(\cdot)$ is increasing, strictly convex and does not include any fixed costs:

Assumption 2.1. 1. $\psi^{\prime} \geq 0$ and $\psi^{\prime \prime}>0$.

2. $\psi(0)=0$ and $\psi^{\prime}(0)=0$.

\subsection{Incentive Feasible Allocation}

We will now define incentive feasible allocations for the risk-sharing environment described in the previous section. ${ }^{8}$. An allocation $\left(\left\{c^{i}\right\}_{i \in I}, d\right) \in C^{I} \times D$ is given by a consumption process for each agent and a process of punishment levels. An allocation is feasible if

$$
\left(\sum_{i \in I} c^{i}\left(\omega_{t}, s\right)\right)+\psi\left(d\left(\omega_{t}\right)\right) \leq Y \text { for all } t,\left(\omega_{t}, s\right) .
$$

An agent can switch to autarky for any given state $s$ at time $t$. Her decision will depend on the comparison between the continuation utility offered by an allocation and the value of autarky given the current level of punishment. Since we are interested in voluntary

\footnotetext{
${ }^{8}$ For a more detailed discussion on the set up as well as the concept of incentive feasibility in this context see Koeppl (2002).
} 
risk-sharing, we restrict attention to allocations that give every agent an incentive to participate in risk-sharing over time.

Definition 2.2. An allocation $\left(\left\{c^{i}\right\}_{i \in I}, d\right) \in C^{I} \times D$ is ex post incentive compatible if it satisfies

$$
u_{i}\left(c^{i}\left(\omega_{t}, s\right)\right)+E_{t}\left[\sum_{\tau=1}^{\infty} \beta^{\tau} u_{i}\left(c_{t+\tau}^{i}\right)\right] \geq\left(1-d\left(\omega_{t}\right)\right)\left[u_{i}\left(y_{t, s}^{i}\right)+\beta V_{a u t}^{i}\right]
$$

for all $i \in I$, for all $t, s$. An allocation is incentive feasible if it is feasible for all $t,\left(\omega_{t}, s\right)$ and ex post incentive compatible for all $i \in I$, for all $t,\left(\omega_{t}, s\right)$.

For the reminder of the paper we denote the set of incentive feasible allocations by $\Gamma \subset C^{I} \times D$.

\subsection{Optimal Allocations}

The concept of incentive feasibility allows us to define optimal allocations. An allocation $\left(\left\{c^{i}\right\}_{i \in I}, d\right) \in \Gamma$ is optimal if there exists no other incentive feasible allocation that provides all agents with at least as much expected utility at period 0 and at least one of them with strictly more expected utility at period 0 . Denoting the initial level of expected utility promised to agent $i$ by $u_{i}^{0}$, optimal allocations can then be described by the following Pareto-problem:

$$
\max _{\left(\left\{c^{i}\right\}_{i \in I}, d\right)} E_{0}\left[\sum_{t=0}^{\infty} \beta^{t} u_{1}\left(c_{t}^{1}\right)\right]
$$

subject to

$$
\begin{aligned}
& \left(\left\{c^{i}\right\}_{i \in I}, d\right) \in \Gamma \\
& E_{0}\left[\sum_{t=0}^{\infty} \beta^{t} u_{i}\left(c_{t}^{i}\right)\right] \geq u_{i}^{0} \text { for all } i \in I \backslash\{1\} .
\end{aligned}
$$


Denote the Lagrange multiplier on the ex-post incentive compatibility constraint (4) of agent $i$ in state $\left(\omega^{t-1}, s\right)$ by $\xi^{i}\left(\omega^{t-1}, s\right)$ and define $\tilde{\xi}^{i}\left(\omega^{t-1}, s\right)=\frac{\xi^{i}\left(\omega^{t-1}, s\right)}{\beta^{t} \pi\left(\omega^{t-1}, s\right)}$. We have then the following first-order necessary conditions with respect to the optimal choice of $c^{i}\left(\omega^{t-1}, s\right)$ and $d\left(\omega^{t-1}\right)$ in period $t$ after history $\omega^{t-1}$ :

$$
\begin{aligned}
& u_{i}^{\prime}\left(c_{i}\left(\omega^{t-1}, s\right)\right)\left[\nu^{i}+\sum_{\omega^{\tau} \prec \omega^{t}} \tilde{\xi}^{i}\left(\omega^{\tau}\right)\right]-\lambda\left(\omega^{t-1}, s\right)=0 \text { for all } i \in I \\
& \psi^{\prime}\left(d\left(\omega^{t-1}\right)\right)=\frac{\sum_{i \in I} \sum_{s \in S} \xi^{i}\left(\omega^{t-1}, s\right)\left[u_{i}\left(y^{i}\left(\omega^{t-1}, s\right)\right)+\beta V_{a u t}\right]}{\sum_{s \in S} \lambda\left(\omega^{t-1}, s\right)},
\end{aligned}
$$

where $\nu^{i}$ (with $\nu^{1}=1$ ) is the Lagrange multiplier on constraint $(7)$ and $\lambda\left(\omega^{t-1}, s\right)$ the multiplier for the resource constraint.

The optimality condition (9) makes it apparent that enforcement through the punishment technology is a public good. It is the classic condition first derived by Samuelson (1954) for the optimal provision of a public good. Operating the technology at a level $d\left(\omega^{t-1}\right)>$ 0 benefits not only one agent, but all agents that are constrained. This is due to the fact that a higher level of $d\left(\omega^{t-1}\right)$ relaxes the ex post incentive compatibility constraints (4) for all agents simultaneously. Hence, it is optimal to equate the marginal costs of using the technology with the sum of marginal benefits that all agents derive from the technology. Note that equation (9) takes into account that not all agents are necessarily constrained. If some agent $i$ is unconstrained, her Lagrange multiplier on the ex post incentive compatibility constraint, $\xi^{i}\left(\omega^{t-1}, s\right)$, is zero indicating that she does not derive any direct marginal benefit from operating the technology even though there is an indirect benefit from better risk sharing.

Summarizing main results for the problem (5) - (7) optimal incentive feasible allocations always exist for the given environment. Furthermore, if the first-best allocation is not incentive feasible, it is always optimal to partially rely on the punishment technology for enforcement since by Assumption 2.1 the marginal costs of the technology at $d\left(\omega^{t-1}\right)=0$ are small. It also is never optimal to set $d\left(\omega^{t-1}\right)=1$ which justifies the equality sign in 
the first-order condition (9). Last, the optimal choice of using the punishment technology is path-dependent, i.e., varies over time with the sequence of realized endowment shocks. ${ }^{9}$ To facilitate the exposition we assume without loss of generality for the remainder of this paper that $u_{i}=u$ for all $i \in I$.

\section{Lindahl Equilibria with Enforcement Intermedi- aries}

We are now taking into account that enforcement - or, more specifically, the punishment technology - has the character of a public good and analyze whether the optimal level of the technology as well as optimal risk sharing can be achieved through a financial markets arrangement. In doing so we rely on ideas captured by the concept of Lindahlequilibrium where the public good is sold on individualized markets for agent-specific prices that reflect the marginal utility of an agent from the public good.

The basic set-up is as follows. There are one-period state-contingent claims that pay in units of the consumption good and are traded competitively. Hence, markets are complete in the sense that there are as many securities as there are realizations of $\omega_{t}$ at period $t$; the size of possible trades, however, is restricted through limits on borrowing in form of "endogenous solvency constraints" as introduced by Alvarez and Jermann (2000). These solvency constraints ensure that agents do not have an incentive to default - or, equivalently, prefer a certain outside option such as autarky. Since default is associated with a specific level of utility, agents are allowed to borrow only up to an amount that gives them exactly this level of life-time utility if they honor their debt and repay the borrowed amount plus interest.

In our environment, people can influence their utility from default by using the punishment technology. The technology itself is operated by a profit maximizing competitive

\footnotetext{
${ }^{9}$ For details on these results see Koeppl (2003).
} 
firm that sells the use of the technology to the agents at agent-specific prices. If an agent does not demand any enforcement through the punishment technology default is punished by permanent exclusion from asset markets and her borrowing constraints is set to reflect this punishment. If an agent, however, demands some enforcement through the technology for a positive price, she reduces her wealth, but is able to relax her borrowing constraints. As we will show later, this set up guarantees the efficient provision of enforcement and - together with agents choosing their borrowing constraints - allows for constrained optimal risk sharing.

\subsection{Enforcement Intermediaries}

The punishment technology is operated by a perfectly competitive firm which will be called the enforcement intermediary. In period $t-1$, after the endowment shocks have been realized, the intermediary supplies a level of punishment $d$ for next period and sells the "right to use" the punishment technology at level $d$ in period $t$ to agent $i$ at the agent-specific price $p_{i}^{e}$ which is quoted in period- $t$ goods. Next period, he collects the payments in period- $t$ goods from last period's sales to the agents and operates the technology at the level he chose last period. Formally, taking agent-specific prices $\left\{p_{i}^{e}\right\}_{i \in I}$ as given, in period $t-1$ the intermediary maximizes next period profits:

$$
\begin{aligned}
& \max _{d\left(\omega^{t-1}\right)} \sum_{i \in I} p_{i}^{e}\left(\omega^{t-1}\right) d\left(\omega^{t-1}\right)-\psi\left(d\left(\omega^{t-1}\right)\right) \\
& \text { subject to } \\
& \qquad d\left(\omega^{t-1}\right) \in[0,1] .
\end{aligned}
$$

The agent-specific prices, $p_{i}^{e}$, are expressed in units of the consumption good at period $t$ and are given by an $\omega^{t-1}$-measurable stochastic process taking positive values for all $\omega^{t-1}$, i.e., $p_{i}^{e}: \Omega^{t-1} \longrightarrow \mathbb{R}_{+}$. The total fee charged to agent $i, p_{i}^{e} d$, is to be interpreted as a direct transfer of resources from agent $i$ to the enforcement intermediary. Since the 
punishment technology is linear with a strictly convex cost function (cf. Assumption 2.1 ), profits will be strictly positive whenever $d>0$. We denote profits in period $t$ given a history of shocks $\omega^{t-1}$ by $\Theta_{t}\left(\omega^{t-1}\right)$. Every period, these profits are then paid out as a lump-sum transfer to the agents that is constant across agents.

Note that the intermediary decides about the level of punishment before period- $t$ endowment shocks are realized. He receives, however, the fees charged to consumers only after the period- $t$ shocks have occurred. Hence, we implicitly assume that the intermediary has one-period commitment, i.e., he will carry out his initial decision once the current shock has been realized and he has received the payments from the agents. Furthermore, we rule out any further incentive problem on part of the intermediary by assuming that he will use the punishment technology in case of default by agents on trades made in the market for state-contingent claims.

The solution to problem (10) after history $\omega^{t-1}$ can be characterized by

$$
\sum_{i \in I} p_{i}^{e}\left(\omega^{t-1}\right)=\psi^{\prime}\left(d\left(\omega^{t-1}\right)\right)
$$

By Assumption 2.1, $d=0$ is a solution to equation (11) only if $p_{i}^{e}=0$ for all $i$. It will become clear later that zero prices for all agents corresponds to a situation where the marginal utility of the technology is zero for everybody. This corresponds to a situation where some first-best consumption allocation is in fact incentive feasible. ${ }^{10}$

\subsection{Asset Markets and Borrowing Constraints}

The asset market structure in period $t$ after a history of shocks $\omega^{t}$ is given by a complete set of one-period state-contingent claims. Let $q\left(\omega^{t}, s\right)$ be the price of a claim in period $t$ after history $\omega^{t}$ to one unit of the consumption good conditional on $\omega_{t+1}=s$. Denote

\footnotetext{
${ }^{10} \mathrm{We}$ are ignoring here the second corner solution, since it is never optimal to operate the technology at $d=1$.
} 
by $a^{i}\left(\omega^{t}, s\right)$ the holdings of such a claim by agent $i$. The stochastic processes of asset holdings of agent $i$ and asset prices are then given by $a^{i}=\left\{\left\{a_{t}^{i}\right\}_{t=1}^{\infty} \mid a_{t}^{i}: \Omega^{t} \longrightarrow \mathbb{R}\right\}$ and $q=\left\{\left\{q_{t}\right\}_{t=1}^{\infty} \mid q_{t}: \Omega^{t} \longrightarrow \mathbb{R}_{+}\right\}$respectively.

Agents invest in these Arrow-Debreu securities to insure against their endowment risk. When doing so they face a full schedule of borrowing constraints that is specific for each security and depends on their demand of the punishment technology. Formally, let $d^{i}=\left\{\left\{d_{t}^{i}\right\}_{t=0}^{\infty} \mid d_{t}^{i}: \Omega^{t-1} \longrightarrow[0,1]\right\}$ be agent $i$ 's demand for the use of the punishment technology which we call from now on borrowing rights. The schedule of borrowing constraints that agent $i$ faces given history $\omega^{t}$ is then denoted by $B_{i}\left(d^{i}\left(\omega^{t}\right),\left(\omega^{t}, s\right)\right)$ for all agents $i \in I$ with the stochastic process given by $B_{i}=\left\{\left\{B_{i, t}\right\}_{t=0}^{\infty} \mid B_{i, t}:[0,1] \times \Omega^{t} \longrightarrow \mathbb{R}\right\}$. We assume that the schedule of borrowing constraints is strictly decreasing and convex. Assumption 3.1. For all $i \in I, B_{i}^{\prime}\left(d^{i}\left(\omega^{t}\right),\left(\omega^{t}, s\right)\right)<0$ and $B_{i}^{\prime \prime}\left(d^{i}\left(\omega^{t}\right),\left(\omega^{t}, s\right)\right) \geq 0$ for all $\left(\omega^{t}, s\right)$.

Denote the wealth of agent $i$ by $w^{i}=\left\{\left\{w_{t}^{i}\right\}_{t=0}^{\infty} \mid w_{t}^{i}: \Omega^{t} \longrightarrow \mathbb{R}\right\}$. Given her wealth, the problem of agent $i$ is then to choose current consumption, a portfolio of state-contingent claims and borrowing rights such as to maximize her utility taking prices and the schedule of constraints as given.

$$
J_{t}\left(w^{i}, \omega^{t}\right)=\max _{c^{i}\left(\omega^{t}\right), d^{i}\left(\omega^{t}\right),\left\{a\left(\omega^{t}, s\right)\right\}_{s \in S}} u\left(c^{i}\left(\omega^{t}\right)\right)+\beta \sum_{s \in S} \pi_{s} J_{t+1}\left(w^{i}\left(\omega^{t}, s\right),\left(\omega^{t}, s\right)\right)
$$

subject to

$$
\begin{aligned}
& y^{i}\left(\omega^{t}\right)+w^{i}=\sum_{s \in S} q\left(\omega^{t}, s\right) a^{i}\left(\omega^{t}, s\right)+c^{i}\left(\omega^{t}\right) \\
& w^{i}\left(\omega^{t}, s\right)=a\left(\omega^{t}, s\right)-p_{i}^{e}\left(\omega^{t}\right) d^{i}\left(\omega^{t}\right)+\frac{\Theta_{t+1}\left(\omega^{t}\right)}{\# I} \text { for all } s \in S \\
& w^{i}\left(\omega^{t}, s\right) \geq B_{i}\left(d^{i}\left(\omega^{t}\right),\left(\omega^{t}, s\right)\right) \text { for all } s \in S .
\end{aligned}
$$

Note that the agent's optimal choices depend only on the total wealth $w$ at the start of a period as defined by (14). The composition of wealth, i.e., payoffs of state-contingent 
claims, profits from the intermediary and costs of having bought additional borrowing rights, does not matter for the agent's choice.

The interpretation of the borrowing constraints (15) is as follows. When choosing her trades in state-contingent claims, agent $i$ is restricted by schedules $B_{i}$. These schedules represent the amount the agent can borrow given she demands a level $d^{i}$ of borrowing rights - or, equivalently, enforcement through the technology. Hence, by Assumption 3.1, she can choose to relax the constraints on her financial trades by buying additional borrowing rights at the agent-specific price $p_{i}^{e}$. The demand for these rights, $d^{i}$, corresponds then to the rights of using the punishment technology to secure the agent's overall debt position.

\subsection{Lindahl-equilibrium for Sequential Security Markets}

Our set up leads us to the following definition of a Lindahl-equilibrium for sequential security markets which we will call simply Lindahl-equilibrium.

Definition 3.2. A Lindahl-equilibrium for schedules of borrowing constraints $\left\{B_{i}\right\}_{i \in I}$ and initial conditions $\left(\left\{a_{0}^{i}\right\}_{i \in I},\left\{p_{i, 0}^{e}\right\}_{i \in I}, d_{0}\right)$ where

$$
\begin{gathered}
\sum_{i \in I} p_{i}^{e}\left(\omega_{0}\right) d_{0}=\psi\left(d_{0}\right), \\
w^{i}\left(\omega_{0}\right) \geq B_{i}\left(d_{0}^{i}, \omega_{0}\right) \text { for all } i \in I, \text { for all } \omega_{0}
\end{gathered}
$$

and

$$
d_{0}^{i}=d_{0} \text { for all } i \in I \text {, }
$$

is given by stochastic processes for security prices and agent-specific prices $\left(q,\left\{p_{i}^{e}\right\}_{i \in I}\right)$, a stochastic process of punishment, $d$, and stochastic processes for asset holdings, consumption and borrowing rights, $\left\{c^{i}, d^{i}, a^{i}\right\}_{i \in I}$, such that

1. $\left\{c^{i}, d^{i}, a^{i}\right\}_{i \in I}$ solve problem (12) - (15) taking $\left(q, p_{i}^{e}, B_{i}\right)$ as given 
2. $d$ solves problem (10) taking $\left\{p_{i}^{e}\right\}_{i \in I}$ as given for all $\omega^{t-1}$, for all $t>1$

3. markets clear, i.e.,

$$
\begin{aligned}
& \sum_{i \in I} c^{i}\left(\omega^{t}, s\right)=Y-\psi\left(d\left(\omega^{t}\right)\right) \text { for all } t,\left(\omega^{t}, s\right) \\
& \sum_{i \in I} a^{i}\left(\omega^{t}, s\right)=0 \text { for all } t,\left(\omega^{t}, s\right) \\
& d^{i}\left(\omega^{t}\right)=d\left(\omega^{t}\right) \text { for all } i, \omega^{t} .
\end{aligned}
$$

For our purpose it is important to look only at equilibria that prevent agents from defaulting. We therefore restrict attention to Lindahl-equilibria where the schedules of borrowing constraints are such that no agent has an incentive to default on any obligations - arising from $a^{i}$ and $p_{i}^{e} d^{i}$ - for any choice of borrowing rights, but otherwise allow for best possible risk sharing given a level of borrowing rights. This is formalized in the definition below.

Definition 3.3. A Lindahl-equilibrium $\left(\hat{q},\left\{\hat{p}_{i}^{e}\right\}_{i \in I}, \hat{d},\left\{\hat{c}^{i}, \hat{d}^{i}, \hat{a}^{i}\right\}_{i \in I}\right)$ has borrowing limits that are not too tight if - given equilibrium prices - the schedules of borrowing constraints $\left\{B_{i}\right\}_{i \in I}$ satisfy

$$
J_{t+1}\left(B_{i}\left(d^{i}\left(\omega^{t}\right),\left(\omega^{t}, s\right)\right),\left(\omega^{t}, s\right)\right)=\left(1-d^{i}\left(\omega^{t}\right)\right)\left[u\left(y_{s}^{i}\right)+\beta V_{a u t}\right]
$$

for all $i,\left(\omega^{t}, s\right)$.

We emphasize that condition (22) is imposed on the whole schedule of borrowing constraints, and not only at the equilibrium level of rights demanded by agent $i$. Condition (22) ensures that no agent has an incentive to default at any level of $d^{i}\left(\omega^{t}\right)$. Given her choice of $d^{i}\left(\omega^{t}\right)$, her future expected utility of borrowing up to the limit $B_{i}\left(d^{i}\left(\omega^{t}\right),\left(\omega^{t}, s\right)\right)$ is equal to her outside option of remaining in autarky forever and being punished at level $d^{i}\left(\omega^{t}\right)$. Since $J_{t}$ is strictly increasing in overall wealth $w$, whenever the schedule of borrowing constraints for agent $i$ satisfies equation (22), agent $i$ has no incentive to default for any choice of $d^{i}$. 
It is also crucial here that we impose the borrowing constraints on the overall level of wealth rather than the size of trades in a particular state-contingent claim. This implies that - for any Lindahl-equilibrium - agents who demanded borrowing rights in the previous period will pay their fees once their endowment shock has been realized in the current period. Hence, Definition 3.3 rules out that agents have an incentive to default on their obligations with the intermediary for any level of borrowing rights they can demand. This is important since it ensures that the enforcement intermediary will for any choice of $d$ - obtain the payments from all agents to operate the technology. This justifies that we have not imposed an incentive compatibility constraint on the problem of the intermediary that would have taken into account that agents could default on the fees charged by the intermediary.

\subsection{Second Welfare Theorem}

By Assumption 3.1 the constraint set of each agent is convex and, hence, strict concavity of the objective function implies that the first-order conditions together with an appropriately defined transversality condition are sufficient for a solution to problem (12) (15). Denote the Lagrange-multiplier on the budget constraint (13) by $\lambda^{i}\left(\omega^{t}\right)$ and the multipliers on the borrowing constraints $(15)$ by $\mu^{i}\left(\omega^{t}, s\right)$. Assuming that $J_{t+1}$ is differentiable with respect to $w^{i}\left(\omega^{t}, s\right)$, the first-order necessary condition with respect to $c^{i}\left(\omega^{t}\right)$ and $a^{i}\left(\omega^{t}, s\right)$ are given by

$$
\begin{gathered}
u^{\prime}\left(c^{i}\left(\omega^{t}\right)\right)-\lambda^{i}\left(\omega^{t}\right)=0 \\
-\lambda^{i}\left(\omega^{t}\right) q\left(\omega^{t}, s\right)+\pi_{s} \beta J_{t+1}^{\prime}\left(w^{i}\left(\omega^{t}, s\right),\left(\omega^{t}, s\right)\right)+\mu^{i}\left(\omega^{t}, s\right)=0 .
\end{gathered}
$$

Since the envelope theorem implies that $J_{t+1}^{\prime}\left(w^{i}\left(\omega^{t}, s\right),\left(\omega^{t}, s\right)\right)=\lambda^{i}\left(\omega^{t}, s\right)$, we obtain the intertemporal Euler equation

$$
\pi_{s} \beta u^{\prime}\left(c^{i}\left(\omega^{t}, s\right)\right)-u^{\prime}\left(c^{i}\left(\omega^{t}\right)\right) q\left(\omega^{t}, s\right)+\mu^{i}\left(\omega^{t}, s\right)=0
$$


where $\mu^{i}\left(\omega^{t}, s\right)=0$ if $w^{i}\left(\omega^{t}, s\right)>B_{i}\left(d^{i}\left(\omega^{t}\right),\left(\omega^{t}, s\right)\right)$ and the first-order condition with respect to the choice of borrowing rights

$$
\sum_{s \in S}\left[\pi_{s} \beta u^{\prime}\left(c^{i}\left(\omega^{t}, s\right)\right) p_{i}^{e}\left(\omega^{t}\right)+\mu^{i}\left(\omega^{t}, s\right)\left[p_{i}^{e}\left(\omega^{t}\right)+B_{i}^{\prime}\left(d^{i}\left(\omega^{t}\right),\left(\omega^{t}, s\right)\right)\right]\right]=0 .
$$

The first term of equation (26) describes the marginal cost of choosing $d^{i}$ associated with the fees paid in every state. The second term describes the net marginal benefit from relaxing the borrowing constraint for every state: on the one hand a higher choice of $d^{i}$ relaxes the constraint by reducing $B_{i}$ and, hence, allows for more consumption smoothing; on the other hand, it tightens the borrowing constraint for every state as the agent's overall wealth is reduced by the fees paid to the intermediary.

Finally, the transversality condition is given by

$$
\lim _{t \rightarrow \infty} E_{0}\left[\beta^{t} \lambda_{t}^{i}\left(w_{t}^{i}-B_{i, t}\left(d^{i}\right)\right)\right]=0
$$

Using the first-order condition (23) we can rewrite this condition as

$$
\lim _{t \rightarrow \infty} \sum_{\omega^{t} \in \Omega^{t}} \pi\left(\omega^{t}\right) \beta^{t} u^{\prime}\left(c^{i}\left(\omega^{t}\right)\right)\left[w^{i}\left(\omega^{t}\right)-B_{i}\left(d^{i}\left(\omega^{t-1}\right), \omega^{t}\right)\right]
$$

Before establishing a version of the Second Welfare Theorem we derive some properties of asset prices and personalized prices for borrowing rights. We first show that unconstrained agents have the highest marginal rate of intertemporal substitution for every optimal allocation. This marginal rate of substitution is later used to determine the asset price process for a Lindahl-equilibrium.

Lemma 3.4. Let $\left(\left\{c^{i}\right\}_{i \in I}, d\right\}$ be an optimal allocation. If for $j \in I$ equation (4) holds with strict inequality for $\left(\omega^{t}, s\right)$, then

$$
\frac{u^{\prime}\left(c^{j}\left(\omega^{t}, s\right)\right)}{u^{\prime}\left(c^{j}\left(\omega^{t}\right)\right)}=\max _{i \in I} \frac{u^{\prime}\left(c^{i}\left(\omega^{t}, s\right)\right)}{u^{\prime}\left(c^{i}\left(\omega^{t}\right)\right)}
$$

Proof. See Appendix. 
Since asset prices will be determined using Lemma 3.4, the only missing part in decentralizing an optimal allocation as a Lindahl-equilibrium with borrowing limits that are not too tight consists, then, of finding agent-specific prices for borrowing rights and schedules of borrowing constraints that satisfy equation (22) for every agent. The next result describes the situation where some agent - or subgroup of agents - does not benefit directly from the punishment technology, i.e., his marginal utility from the public good is zero.

Lemma 3.5. For any Lindahl-equilibrium, $p_{i}^{e}\left(\omega^{t}\right)=0$ if $\mu^{i}\left(\omega^{t}, s\right)=0$ for all $s \in S$.

Proof. See Appendix.

The lemma states that the agent-specific price is strictly positive in equilibrium only if the agent is borrowing constrained for some state $s$ in the next period. In case a firstbest consumption allocation is incentive feasible, this implies that agent-specific prices in a Lindahl-equilibrium with borrowing limits that are not too tight are zero for all agents and, hence, $d=0$. This lemma is not in contradiction to the requirement of Definition 3.2 that all agents demand the same quantity of the good, i.e., $d^{i}=d$ for all $i$. Facing a zero price for borrowing rights while unconstrained an agent is indifferent between any level of $d$. We then assume that the agent demands the right amount of $d$ in equilibrium. ${ }^{11}$

For any agent $i$ that is constrained at least for some state after history $\omega^{t}$, let $S_{i}^{0}$ be the set of states $s$ such that $\mu^{i}\left(\omega^{t}, s\right)>0$. Using the intertemporal Euler equation (25) we obtain

$$
p_{i}^{e}\left(\omega^{t}\right)=\frac{\sum_{s \in S_{i}^{0}}\left[\beta \pi_{s} u^{\prime}\left(c^{i}\left(\omega^{t}, s\right)\right)-u^{\prime}\left(c^{i}\left(\omega^{t}\right)\right) q\left(\omega^{t}, s\right)\right] B_{i}^{\prime}\left(d^{i}\left(\omega^{t}\right),\left(\omega^{t}, s\right)\right)}{\sum_{s \in S_{i}^{0}} u^{\prime}\left(c^{i}\left(\omega^{t}\right)\right) q\left(\omega^{t}, s\right)+\sum_{s \in S \backslash S_{i}^{0}} \beta \pi_{s} u^{\prime}\left(c^{i}\left(\omega^{t}, s\right)\right)} .
$$

For any Lindahl-equilibrium where borrowing constraints are not too tight we must have that for any given $\left(\omega^{t}, s\right)$

\footnotetext{
${ }^{11}$ Alternatively, one could require in Definition 3.2 that $d^{i}=d$ for all $i$ such that $d^{i}>0$.
} 


$$
B_{i}\left(d^{i}\left(\omega^{t}\right),\left(\omega^{t}, s\right)\right)=\left.J^{-1}\right|_{\left(\omega^{t}, s\right)}\left(\left(1-d^{i}\left(\omega^{t}\right)\right)\left[u\left(y_{t, s}^{i}\right)+\beta V_{a u t}\right]\right)
$$

which is well defined since the function $J$ is strictly increasing in wealth. Assuming again that $J$ is differentiable, differentiating $B_{i}$ with respect to $d^{i}$ yields

$$
B_{i}^{\prime}\left(d^{i}\left(\omega^{t}\right),\left(\omega^{t}, s\right)\right)=\frac{1}{J^{\prime}\left(\left(1-d^{i}\left(\omega^{t}\right)\right)\left[u\left(y_{t, s}^{i}\right)+\beta V_{a u t}\right],\left(\omega^{t}, s\right)\right)}
$$

Let the asset price process $q$ be defined for a given allocation $\left(\left\{c^{i}\right\}_{i \in I}, d\right)$ by

$$
q\left(\omega^{t}, s\right)=\max _{i \in I} \beta \pi\left(\omega^{t}, s\right) \frac{u^{\prime}\left(c^{i}\left(\omega^{t}, s\right)\right)}{u^{\prime}\left(c^{i}\left(\omega^{t}\right)\right)} \text { for all }\left(\omega^{t}, s\right) .
$$

It follows from Lemma 3.4 and equation (33) that

$$
p_{i}^{e}\left(\omega^{t}\right)=\frac{\sum_{s \in S}\left[\beta \pi_{s} u^{\prime}\left(c^{i}\left(\omega^{t}, s\right)\right)-u^{\prime}\left(c^{i}\left(\omega^{t}\right)\right) q\left(\omega^{t}, s\right)\right] B_{i}^{\prime}\left(d^{i}\left(\omega^{t}\right),\left(\omega^{t}, s\right)\right)}{\sum_{s \in S} u^{\prime}\left(c^{i}\left(\omega^{t}\right)\right) q\left(\omega^{t}, s\right)} .
$$

This is due to the fact that for unconstrained agents the definition of the asset price process equates the marginal rate of substitution with the price of the state-contingent claim. Furthermore, the terms in the sum of the numerator are only non-zero if the borrowing constraints for a state $s$ is binding. Using equation (32) and the envelope theorem, for any Lindahl-equilibrium that has borrowing limits which are not too tight personalized prices for borrowing rights have to be equal to

$$
p_{i}^{e}\left(\omega^{t}\right)=\frac{\sum_{s \in S}\left[\beta \pi_{s} u^{\prime}\left(c^{i}\left(\omega^{t}, s\right)\right)-u^{\prime}\left(c^{i}\left(\omega^{t}\right)\right) q\left(\omega^{t}, s\right)\right] \frac{-\left[u\left(y_{t, s}^{i}\right)+\beta V_{a u t}\right]}{u^{\prime}\left(c^{i}\left(\omega^{t}, s\right)\right)}}{\sum_{s \in S} u^{\prime}\left(c^{i}\left(\omega^{t}\right)\right) q\left(\omega^{t}, s\right)}
$$

These prices reflect that the marginal benefit agent $i$ derives from operating the punishment technology at $d\left(\omega^{t}\right)$ which is zero if the agent is not borrowing constrained (cf. Lemma 3.5). If we substitute this expression together with the optimality condition of the public good $d$, equation (9), into the first-order condition of the intermediary (11), 
it is apparent that $d\left(\omega^{t}\right)$ maximizes profits given history $\omega^{t}$ and prices $p_{i}^{e}\left(\omega^{t}\right)$ for all $i$. Finally, we introduce the following condition on the asset price process. ${ }^{12}$

Definition 3.6. Let $Q_{0}\left(\omega^{t} \mid \omega_{0}\right)=q\left(\omega_{0}, \omega_{1}\right) q\left(\omega^{1}, \omega_{2}\right) \cdots q\left(\omega^{t-1}, \omega_{t}\right)$. Interest rates are high if

$$
\sum_{t=1}^{\infty} \sum_{\omega^{t} \in \Omega^{t}} Q_{0}\left(\omega^{t} \mid \omega_{0}\right)<\infty \text { for all } \omega_{0}
$$

This leads directly to our main result - decentralizing a given optimal allocation as a Lindahl-equilibrium with borrowing limits that are not too tight - which is stated below. ${ }^{13}$ This result is also important in the sense that it shows the existence of Lindahl-equilibria under very weak restrictions.

Theorem 3.7. Let $\left(\left\{c^{i}\right\}_{i \in I}, d\right)$ be an optimal allocation. Suppose the security price process defined by equation (33) has high interest rates and agent-specific prices are given by equation (35). Then there exist initial conditions $\left(\left\{a_{0}^{i}\right\}_{i \in I},\left\{p_{i, 0}^{e}\right\}_{i \in I}, d_{0}\right)$, asset holdings and schedules of borrowing constraints, $\left(\left\{a^{i}\right\}_{i \in I},\left\{B_{i}\right\}_{i \in I}\right)$, such that the security price process defined by equation (33), the agent-specific prices defined by equation (35), the schedule of borrowing constraints, the supply of punishment, $d$, and the demands by agents, $\left\{c^{i}, d^{i}, a^{i}\right\}_{i \in I}$, where $d^{i}=d$ for all $i \in I$, are a Lindahl-equilibrium with borrowing limits that are not too tight.

Proof. See Appendix.

\footnotetext{
${ }^{12}$ In a related context, Alvarez and Jermann (2000) show in their Proposition 4.10 that implied interest rates are high given an optimal allocation that exhibits some risk sharing. Since it can be shown that some risk sharing is always feasible as long as we have $\psi^{\prime}(0)=0$, we conclude that for our framework, the condition of high implied interest rates is fulfilled for every optimal allocation.

${ }^{13}$ It is straightforward to also decentralize the initial level $d_{0}$ at which the punishment technology is operated. One has to look at the initial problem for an agent of choosing her borrowing constraints at $t=0$ for each $\omega_{0}$ and paying an agent-specific price $p_{i, 0}^{e}$ for borrowing rights $d_{0}^{i}$.
} 


\section{Optimality of Lindahl-Equilibria}

Having shown that Lindahl-equilibria can implement efficient outcomes, this leaves the question whether financial markets where intermediaries provide costly enforcement always achieve efficient outcomes. The methodology to address this question is straightforward. First, we transform any Lindahl-equilibrium with sequential markets into an equilibrium of a corresponding Arrow-Debreu economy with participation constraints that restrict the feasible consumption set along the lines of Kehoe and Levine (1993). The proof of the First Welfare Theorem is then completely standard and follows as a corollary.

For this purpose we define an Arrow-Debreu pricing functional $p_{0}$ that assigns a price to any vector in the consumption space. Hence, $p_{0}: C \longrightarrow \mathbb{R}_{+}$, where $C$ is the set of all possible consumption plans for a consumer. Whenever $p_{0}$ is countably additive, the value of this pricing functional for any $c \in C$ can be expressed as

$$
p_{0}(c)=\sum_{t=0}^{\infty} \sum_{\omega^{t} \in \Omega^{t} \mid \omega_{0}} c\left(\omega^{t}\right) Q_{0}\left(\omega^{t} \mid \omega_{0}\right)
$$

where $Q_{0}\left(\omega^{t} \mid \omega_{0}\right)$ is the period 0 price of one unit of the consumption good in state $\omega^{t}$ conditional on the first period shock $\omega_{0}$ and $Q\left(\omega_{0} \mid \omega_{0}\right) \equiv 1$. For a countably additive pricing functional the problem of agent $i$ given $\omega_{0}$ becomes then

$$
\max _{c^{i}, d^{i}} E_{0}\left[\sum_{t=0}^{\infty} \beta^{t} u\left(c^{i}\right) \mid \omega_{0}\right]
$$

subject to

$$
\begin{aligned}
& p_{0}\left(c^{i}+p_{i}^{e} d^{i}\right)-p_{0}\left(y^{i}+\frac{\Theta}{\# I}\right) \leq w_{0}^{i} \\
& u_{i}\left(c^{i}\left(\omega^{t}, s\right)\right)+E_{t}\left[\sum_{\tau=1}^{\infty} \beta^{\tau} u_{i}\left(c_{t+\tau}^{i}\right)\right] \geq\left(1-d^{i}\left(\omega^{t}\right)\right)\left[u_{i}\left(y_{t, s}^{i}\right)+\beta V_{\text {aut }}\right] \text { for all }\left(\omega^{t}, s\right) .
\end{aligned}
$$


Intermediaries solve an intertemporal maximization problem. Prices for enforcement are still quoted in terms of the consumption good, but transformed into a net present value by using the pricing functional $p_{0}$. Hence, assuming $p_{0}$ is countably additive intermediaries solve

$$
\max _{d} \sum_{t=1}^{\infty} \sum_{\omega^{t} \in \Omega^{t} \mid \omega_{0}} Q_{0}\left(\omega^{t} \mid \omega_{0}\right)\left(\sum_{i \in I} p_{i}^{e}\left(\omega^{t-1}\right) d\left(\omega^{t-1}\right)-\psi\left(d\left(\omega^{t-1}\right)\right)\right)
$$

subject to

$$
d\left(\omega^{t-1}\right) \in[0,1] \text { for all } t, \omega^{t-1} .
$$

This leads us to a definition of the equilibrium concept developed by Kehoe and Levine (1993).

Definition 4.1. A Kehoe-Levine equilibrium for given initial conditions $\left(d_{0},\left\{w_{0}^{i}, p_{i, 0}^{e}\right\}_{i \in I}\right)$ where

$$
\sum_{i \in I} p_{i, 0}^{e} d_{0}=\psi\left(d_{0}\right)
$$

and

$$
d_{0}^{i}=d_{0} \text { for all } i \in I \text {, }
$$

is given by stochastic processes for consumption and individual demands for enforcement $\left\{c^{i}, d^{i}\right\}_{i \in I}$, a stochastic process of punishments $d$, a pricing functional $p_{0}$ and stochastic processes of agent-specific prices $\left\{p_{i}^{e}\right\}_{i \in I}$ such that

1. $\left\{c^{i}, d^{i}\right\}$ solve problem (38) - (40) taking $p_{0}$ and $p_{i}^{e}$ as given

2. $d$ solves problem (38) taking $p_{0}$ and $p_{i}^{e}$ as given

3. markets clear, i.e. equations (19) and (21) hold. 
By using a variational argument, from the first-order necessary conditions of the consumer's problem one can easily verify that for any Kehoe-Levine equilibrium the pricing functional $p_{0}$ is countably additive and satisfies

$$
q_{0}\left(\omega^{t}, s\right)=\frac{Q_{0}\left(\omega^{t}, s \mid \omega^{t}\right)}{Q_{0}\left(\omega^{t} \mid \omega_{0}\right)}=\max _{i \in I} \beta \pi_{s} \frac{u\left(\hat{c}^{i}\left(\omega^{t}, s\right)\right)}{u\left(\hat{c}^{i}\left(\omega^{t}\right)\right)},
$$

where $\hat{c}^{i}$ is consumption of agent $i$ in equilibrium. The prices $q_{0}\left(\omega^{t}, s\right)$ are the ArrowDebreu prices implied by the pricing functional $p_{0}$. Whenever interest rates are high, the pricing functional $p_{0}$ is finitely valued and, therefore, the problems of the agents and the intermediary are always well defined in this case.

Similarly, given the pricing functional fulfills condition (44), one can verify through a variational argument that for any Kehoe-Levine equilibrium agent-specific prices are given by

$$
\tilde{p}_{i}^{e}\left(\omega^{t}\right)=\frac{\sum_{s \in S}\left[\beta \pi_{s} u^{\prime}\left(\hat{c}^{i}\left(\omega^{t}, s\right)\right)-u^{\prime}\left(\hat{c}^{i}\left(\omega^{t}\right)\right) q_{0}\left(\omega^{t}, s\right)\right] \frac{-\left[u\left(y_{t, s}^{i}\right)+\beta V_{a u t}\right]}{u^{\prime}\left(\hat{c}^{i}\left(\omega^{t}, s\right)\right)}}{\sum_{s \in S} u^{\prime}\left(\hat{c}^{i}\left(\omega^{t}\right)\right) q_{0}\left(\omega^{t}, s\right)} .
$$

This allows us to prove the equivalence of Kehoe-Levine equilibria and Lindahl-equilibria provided interest rates are high and the consumption process in Lindahl-equilibrium is strictly bounded away from zero for every agent. As mentioned earlier, since optimal allocation are always different from autarky, it follows that interest rates are high given any optimal allocation. From this follows immediately a version of the First Welfare Theorem since preferences are monotone and given the form of the participation constraints (40) we have a standard, convex Arrow-Debreu economy.

The intuition for this result is simple. From equation (40) it is clear that the equilibrium pricing functional is equivalent to the price process for state-contingent claims in a Lindahl-equilibrium. The crucial step then involves expressing the schedule of borrowing limits as participation constraints and verifying that the enforcement choice $d^{i}$ is still optimal given the optimal agent-specific price $\tilde{p}_{i}^{e}$ for the agents when facing participation 
constraints rather than borrowing limits. This is, however, ensured by the strong requirement that borrowing constraints are not too tight for every value of $d^{i}$. The borrowing constraints reflect, then, exactly the participation constraints (40).

Theorem 4.2. Let $\left(\left\{c^{i}, d^{i}, a^{i}\right\}_{i \in I}, q,\left\{p_{i}^{e}\right\}_{i \in I}\right)$ be a Lindahl-equilibrium for which the schedule of borrowing limits are not too tight. Suppose that interest rates are high in equilibrium. Then, $\left(\left\{c^{i}, d^{i}\right\}_{i \in I}, d,\left\{\tilde{p}_{i}^{e}\right\}_{i \in I}, p_{0}\right)$ is a Kehoe-Levine equilibrium for initial conditions $\left(d_{0},\left\{a_{0}^{i}, p_{i, 0}^{e}\right\}_{i \in I}\right)$ where $p_{0}$ is given by (44) and $\tilde{p}_{i}^{e}$ by equation (45).

Proof. See Appendix.

Corollary 4.3. Any Lindahl-equilibrium for with the borrowing constraints are not too tight and interest rates are high is constrained efficient.

\section{$5 \quad$ Asset Pricing Implications}

We already pointed out that borrowing costs can be decomposed into two components: a claim-specific price that reflects the scarcity of funds and an additional premium that reflects costs associated with default. People that are unconstrained in state $s$ trade state-contingent claims at the price $q\left(\omega^{t-1}, s\right)$.

Constrained people, however, have to pay a higher price for the same claim. If agent $i$ is constrained in state $s$, he still pays $q\left(\omega^{t-1}, s\right)$ for buying $a\left(\omega^{t-1}, s\right)$ state-contingent claims, but obtains a pay-off of only $a(\cdot)-p_{i}^{e}\left(\omega^{t-1}\right) d^{i}(a(\cdot))$, where $d^{i}(a)>0$ expresses the amount of borrowing rights agent $i$ has to buy at price $p_{i}^{e}>0$ to carry out this trade. Hence, the return on this trade is given by $\frac{1}{q_{s}}\left(1-\frac{p_{i}^{e} d^{i}(a)}{a}\right)$.

In a Lindahl-equilibrium, the effective rate of borrowing, $R^{i}\left(\omega^{t-1}\right)$, is then given for all agents by

$$
\hat{R}^{i}\left(a, \omega^{t-1}\right)=\frac{1}{\sum_{s} \hat{q}\left(\omega^{t-1}, s\right)}\left(1-\frac{\hat{p}_{i}^{e}\left(\omega^{t-1}\right) d^{i}\left(a\left(\left(\omega^{t-1}\right)\right)\right.}{a}\right),
$$


where $a$ is a portfolio of state-contingent claims that pays $a$ in every state $s$ after history $\omega^{t-1}$. Hence, for $a<0$ we have $\frac{1}{\sum_{s} \hat{q}_{s}}<\hat{R}^{i}(a)$ or, equivalently, there is a positive spread between borrowing and lending in equilibrium for agents that are constrained. ${ }^{14}$

We analyze now how interest rates in Lindahl-equilibrium compare to the ones with first-best risk sharing in a standard Arrow-Debreu economy. There are two effects on interest rates. First, enforcement is costly and - as shown in Koeppl (2002) - varies over time in an optimal allocation. Hence, even though there is no aggregate risk in the economy, total resources available for consumption in equilibrium change over time as well. Whenever enforcement increases from one period to the next, people have an incentive to intertemporally smooth consumption with the result that interest rates tend to be lower.

Second, if a positive amount of resources is spent on the enforcement technology, people share less risk in the optimal allocation than in the first-best. With our decentralization this implies as in Alvarez and Jermann (2000) that people borrow less than in the standard Arrow-Debreu economy. This is only compatible with equilibrium if interest rates are relatively lower. These findings are summarized in the proposition below.

Proposition 5.1. Let $\left(\left\{\hat{c}^{i}\right\}_{i \in I}, \hat{d}\right)$ be an optimal allocation. If $\hat{d}\left(\omega^{t-1}\right) \leq \hat{d}\left(\omega^{t}\right)$, then $q\left(\omega^{t}, s\right) \geq \beta \pi_{s}$ in the corresponding Lindahl-equilibrium. Otherwise, $\sum_{s} q\left(\omega^{t}, s\right)>\beta$ if and only if there exists $i \in I$ such that $E\left[u^{\prime}\left(\hat{c}^{i}\left(\omega^{t}, s\right)\right)\right]>u^{\prime}\left(\hat{c}^{i}\left(\omega^{t}\right)\right)$.

Proof. See Appendix.

This result shows that the two effects can influence interest rates in different directions. This is the case when third-party enforcement decreases over time. Whether the risk sharing effect or the resource effect dominates depends on the comovement of $d$ and individual consumption. As long as there is one person for which consumption declines in expected terms from one period to the next, interest rates are lower than in a comparable

\footnotetext{
${ }^{14}$ Interestingly, in case a constrained agent wants to save, the interest rate for saving in a risk-free asset is strictly lower than the one for unconstrained agents.
} 
Arrow-Debreu economy. The costs of borrowing for individual consumers can of course be considerably higher due to the additional fees charged for borrowing rights.

\section{Discussion}

The concept of Lindahl-equilibrium is based on several implicit assumptions. The most crucial one is the existence of agent-specific markets for the public good which seems to be in contradiction to price-taking behavior by agents. However, one can reinterpret having $I$ agents as rather having $I$ different types of agents each being a continuum with measure one.

More importantly is the criticism that the existence of agent-specific markets requires the exclusivity of trades in the public good. Agents are not allowed to trade on markets that are set up specifically for another agent. This requires not only information ${ }^{15}$ about which agents trade on which markets, but also preventing agents from acquiring the public good on the wrong market or, equivalently, for the wrong price. Hence, an enforcement problem different from the one studied here seems to become important.

Since we assume public information about the identity of the agents, it is reasonable to argue that the punishment technology is also used to punish agents that pay a different than their agent-specific price for the public good. Such free-riding after a particular history of shocks would be punished with autarky forever plus the current utility penalty. In fact, by condition (22), the extreme case of not paying the fee at all is ruled out in equilibrium.

\footnotetext{
${ }^{15}$ The concept of Lindahl-equilibrium has recently been applied to the literature on asymmetric information. In particular, Bisin and Gottardi (2000) have used the concept to internalize externalities inherent in adverse selection economies. Their approach naturally relies on extending the market structure to internalize all external effects. Most interestingly, however, in their approach agents have the choice to declare their type. Trades are required to be incentive compatible, so that agents will reveal their type truthfully. One could envision employing their approach here to analyze problems of information revelation between the intermediary and the agents.
} 
A related issue concerns the production side of the equilibrium concept. There is a single firm or intermediary that produces the public good taking prices on the markets for each agent as given. Given convex costs and a linear technology to produce punishment, this firm makes strictly positive profits whenever these prices are positive. Hence, interpreting the firm as privately owned there should be entry until zero profits are made. This criticism can be addressed by arguing that entry is prohibited and the firm is regulated to behave as a price taker producing the public good in a profit maximizing way. This implies that there must be a public authority or government - not modelled here - that implements agent-specific prices on the consumption side, while giving the firm the right incentives to produce the right quantity of the public good. We do not regard our modelling choice here as an accurate description of how public goods are generally provided for. Our analysis simply shows that it is sufficient to have a competitive intermediary operate the technology for decentralizing optimal allocations.

Another comment concerns the ability of the intermediary to commit for one period. In light of this assumption the enforcement problem seems not to be solved, but merely shifted from the consumption to the production side. The problem here is not so much default by the intermediary in the sense that he does not operate the technology once he has received the payments from the agents; the payments and operating the technology could be reinterpreted as direct exchanges or spot transactions after the shocks have occurred with the punishment technology being set for next period. The real issue is whether there is an incentive for some of the agents and the intermediary to jointly revise the original decision concerning the punishment technology. This can be seen as renegotiation - or even as an intermediary influenced by partial interests. One possible way to address this issue is to model the ownership structure of the intermediary via shares traded among agents on the asset market. Given the possibility of default by agents, markets are incomplete. Hence, there will be a conflict between owners about the optimal plan of the firm which implies that the proper objective of such a privately owned firm might not be clear altogether. It would then be intriguing to analyze whether a particular ownership structure of the intermediary could actually solve the commitment problem associated with operating the punishment technology. 
A short-coming of the Lindahl-equilibrium concept remains that the schedule of borrowing constraints is not a choice variable for the enforcement intermediary. It is left unanswered by our work how the schedules of borrowing constraints are set and who sets them, since the only requirement we impose is that they preclude default in equilibrium (cf. Assumption 3.1). Even though our concept is then well short of a theory of how borrowing constraints are set on competitive asset markets, it potentially offers a way to endogenize the structure of these markets.

Suppose intermediaries compete by operating the punishment technology and by offering schedules of borrowing constraints. Agents choose a borrowing constraint from a schedule thereby self-selecting how much they want to borrow and at which cost. Costs for borrowing are different across agents, since they pay fees to relax their borrowing constraints which are additional costs of borrowing besides interest payments. Together with the price of a state-contingent claim - or the interest charged - they are the total cost of going short in this claim. Whereas the price for the claim is linear, these fees are not. Hence, borrowing takes place at non-linear prices; moreover, while prices are the same for all agents when borrowing a certain amount, the total cost is different across agents.

This approach has the potential to gain insights in the equilibrium structure of interest rates for different levels of borrowing as well as demand and supply structures for intertemporal borrowing. These insights will be important to shape future work that addresses organization of financial markets. In this respect the contribution of this chapter must be strictly seen as a mere starting point towards a full fledged theory of truly endogenous borrowing constraints. 


\section{Appendix}

\section{Proof of Lemma 3.4:}

Proof. The proof is identical to Alvarez and Jermann (2000), but is given for completeness. Let $\left(\left\{c^{i}\right\}_{i \in I}, d\right)$ be an optimal allocation. Suppose there exists $j \in I$ such that

$$
u\left(c^{j}\left(\omega^{t}, s\right)\right)+E_{t+1, s}\left[\sum_{\tau \geq 1}^{\infty} \beta^{\tau} u\left(c_{t+1+\tau}^{j}\right)\right]>\left(1-d_{t+1}\right)\left[u\left(y^{j}\left(\omega^{t}, s\right)\right)+\beta V_{a u t}\right]
$$

but condition (29) does not hold. Then there exists some $i \in I$ with a strictly higher intertemporal marginal rate of substitution than $j$. Since for agent $j$ the ex post incentive compatibility constraint is not binding for $\left(\omega^{t}, s\right)$, we can decrease $c^{j}\left(\omega^{t}, s\right)$ and increase $c^{j}\left(\omega^{t}\right)$ slightly so as to keep her overall continuation utility after history $\omega^{t}$ constant. If we decrease $c^{i}\left(\omega^{t}\right)$ and increase $c^{i}\left(\omega^{t}, s\right)$ by the corresponding amounts, we increase agent $i$ 's overall expected utility given $\omega^{t}$ since his marginal rate of substitution is strictly higher than $j$ 's. Since this does not violate the ex-post incentive feasibility constraints for $\omega^{t}$ nor $\left(\omega^{t}, s\right)$, the allocation can not be optimal. A contradiction.

\section{Proof of Lemma 3.5:}

Proof. Let $\mu^{i}\left(\omega^{t}, s\right)=0$ for all $s$ for some $i$. Then, the first-order necessary condition (22) reduces to

$$
\sum_{s \in S} \pi_{s} \beta u^{\prime}\left(c^{i}\left(\omega^{t}, s\right)\right) p_{i}^{e}\left(\omega^{t}\right)=0
$$

Using the fact that $u^{\prime}\left(c^{i}\left(\omega^{t}, s\right)\right)>0$, it follows that $p_{i}^{e}\left(\omega^{t}\right)=0$ for all $s$.

\section{Proof of Theorem 3.7:}

Proof. The proof is by construction. Let $\left(\left\{\hat{c}^{i}\right\}_{i \in I}, \hat{d}\right)$ be an optimal allocation. Define the security price process $\hat{q}$ by equation (33) and define further $\hat{Q}_{t}\left(\omega^{t+\tau} \mid \omega^{t}\right)=$ 
$\hat{q}\left(\omega^{t}, s\right) \cdot \ldots \cdot \hat{q}\left(\omega^{t+\tau-1}, s\right)$ for $\tau>0$. Next, given the optimal allocation and asset prices $\hat{q}$ we use equation (35) to define agent-specific prices $\hat{p}_{i}^{e}$.

Claim: For the process of asset prices $\hat{q}$ and agent-specific prices $\left\{\hat{p}_{i}^{e}\right\}_{i \in I}$, the solution to the problem of the enforcement intermediary is $\hat{d}\left(\omega^{t}\right)$ for all $\omega^{t}$.

There exists some $j \in I$ for whom constraint (4) does not bind for the optimal allocation. Then, from the first-order necessary condition (8) at $\omega^{t}$ and $\left(\omega^{t}, s\right)$ for agent $j$ and the definition of asset prices we obtain

$$
\frac{\beta \pi_{s} u^{\prime}\left(\hat{c}^{i}\left(\omega^{t}, s\right)\right)}{u^{\prime}\left(\hat{c}^{i}\left(\omega^{t}\right)\right)}=\hat{q}\left(\omega^{t}, s\right)=\frac{\lambda\left(\omega^{t}, s\right)}{\lambda\left(\omega^{t}\right)} .
$$

Hence, for any agent $i$ we again obtain from the first-order necessary condition of optimality (8) at $\omega^{t}$ and $\left(\omega^{t}, s\right)$ for the price $\hat{p}_{i}^{e}$

$$
\begin{aligned}
\hat{p}_{i}^{e}\left(\omega^{t}\right) & = \\
& =\frac{\sum_{s \in S}\left[\beta \pi_{s} u^{\prime}\left(c^{i}\left(\omega^{t}, s\right)\right)-u^{\prime}\left(c^{i}\left(\omega^{t}\right)\right) q\left(\omega^{t}, s\right)\right] \frac{-\left[u\left(y_{s}^{i}\right)+\beta V_{a u t}\right]}{u^{\prime}\left(c^{i}\left(\omega^{t}, s\right)\right)}}{\sum_{s \in S} u^{\prime}\left(c^{i}\left(\omega^{t}\right)\right) q\left(\omega^{t}, s\right)} \\
& =\sum_{s \in S} \frac{-\left[u\left(y_{s}^{i}\right)+\beta V_{a u t}\right]}{u^{\prime}\left(c^{i}\left(\omega^{t}, s\right)\right)} \frac{1}{u^{\prime}\left(c^{i}\left(\omega^{t}\right)\right)\left(\sum_{s \in S} q\left(\omega^{t}, s\right)\right)} \frac{(-1) \tilde{\xi}^{i}\left(\omega^{t}, s\right) \beta \pi_{s} u^{\prime}\left(c^{i}\left(\omega^{t}, s\right)\right)}{\left[\nu^{i}+\sum_{\omega^{\tau} \prec \omega^{t}} \tilde{\xi}^{i}\left(\omega^{\tau}\right)\right]} \\
& =\sum_{s \in S} \frac{\left[u\left(y_{s}^{i}\right)+\beta V_{a u t}\right] \tilde{\xi}^{i}\left(\omega^{t}, s\right) \beta^{t+1} \pi\left(\omega^{t+1}\right)}{\beta^{t} \pi\left(\omega^{t}\right) u^{\prime}\left(c^{i}\left(\omega^{t}\right)\right)\left(\sum_{s \in S} q\left(\omega^{t}, s\right)\right)\left[\nu^{i}+\sum_{\omega^{\tau} \prec \omega^{t}} \tilde{\xi}^{i}\left(\omega^{\tau}\right)\right]} \\
& =\sum_{s \in S} \frac{\left[u\left(y_{s}^{i}\right)+\beta V_{a u t}\right] \xi^{i}\left(\omega^{t}, s\right)}{\left(\sum_{s \in S} q\left(\omega^{t}, s\right)\right) \lambda\left(\omega^{t}\right)} \\
& =\frac{\sum_{s \in S} \xi^{i}\left(\omega^{t}, s\right)\left[u\left(y_{s}^{i}\right)+\beta V_{a u t}\right]}{\sum_{s \in S} \lambda\left(\omega^{t}, s\right)} .
\end{aligned}
$$

Summing agent-specific prices over all agents $i$ we obtain from equation (9) that

$$
\sum_{i \in I} \hat{p}_{i}^{e}\left(\omega^{t}\right)=\psi^{\prime}\left(\hat{d}\left(\omega^{t}\right)\right)
$$

which shows that condition (11) holds. Hence, given agent-specific prices $\hat{p}_{i}^{e}\left(\omega^{t}\right)$ the intermediary produces $\hat{d}\left(\omega^{t}\right)$. 
To prove that the optimal allocation is a solution to the agent's problem, let the process of asset holdings of agent $i$ be given by the difference of the present value of consumption net of endowment including profits and net of fees for enforcement, i.e.,

$$
\begin{aligned}
& \hat{a}^{i}\left(\omega^{t}\right)=\hat{c}^{i}\left(\omega^{t}\right)-\left(y^{i}\left(\omega^{t}\right)-\hat{p}_{i}^{e}\left(\omega^{t-1}\right) \hat{d}\left(\omega^{t-1}\right)+\frac{\hat{\Theta}_{t}\left(\omega^{t-1}\right)}{\# I}\right)+ \\
& \sum_{\tau>t} \sum_{\omega^{\tau} \in\left(\Omega^{\tau} \mid \omega^{t}\right)} \hat{Q}_{t}\left(\omega^{\tau} \mid \omega^{t}\right)\left[\hat{c}^{i}\left(\omega^{\tau}\right)-\left(y^{i}\left(\omega^{\tau}\right)-\hat{p}_{i}^{e}\left(\omega^{\tau-1}\right) \hat{d}\left(\omega^{\tau-1}\right)+\frac{\hat{\Theta}_{t}\left(\omega^{\tau-1}\right)}{\# I}\right)\right]
\end{aligned}
$$

for all $t>0$ and $\omega^{t} \in \Omega^{t}$.

For now we define the schedules of borrowing constraints as linear decreasing functions on the interval $[0,1]$ for all $\left(\omega^{t}, s\right)$. Define the slope of these functions by equation $(32)$ or

$$
B_{i}^{\prime}\left(d^{i}\left(\omega^{t}\right),\left(\omega^{t}, s\right)\right)=\frac{1}{u^{\prime}\left(c^{i}\left(\omega^{t}, s\right)\right)}
$$

Define the intercept of these functions as follows:

- If the ex post incentive compatibility constraint is binding for agent $i$ in state $\left(\omega^{t}, s\right)$, let

$$
B_{i}\left(\hat{d}^{i}\left(\omega^{t}\right),\left(\omega^{t}, s\right)\right)=\hat{a}^{i}\left(\omega^{t}, s\right)-\hat{p}_{i}^{e}\left(\omega^{t}\right) \hat{d}\left(\omega^{t}\right)+\frac{\hat{\Theta}_{t+1}\left(\omega^{t}\right)}{\# I} .
$$

- Otherwise, let

$$
\begin{aligned}
& B_{i}\left(\hat{d}^{i}\left(\omega^{t}\right),\left(\omega^{t}, s\right)\right)= \\
& \quad-\sum_{\tau>t} \sum_{\omega^{\tau} \in\left(\Omega^{\tau} \mid \omega^{t}\right)} \hat{Q}_{t}\left(\omega^{\tau} \mid \omega^{t}\right)\left(y^{i}\left(\omega^{\tau}\right)-\hat{p}_{i}^{e}\left(\omega^{\tau-1}\right) d\left(\omega^{\tau-1}\right)+\frac{\hat{\Theta}_{t}\left(\omega^{\tau-1}\right)}{\# I}\right)
\end{aligned}
$$

Similarly, it is straightforward to define initial borrowing schedules, asset portfolios and agent-specific fees such that the restrictions on the initial conditions of Definition 3.2 are fulfilled and $\hat{d}_{0}$ satisfies equation (16). 
Claim: The processes for consumption, asset holdings and borrowing rights $\left(\hat{c}^{i}, \hat{a}^{i}, \hat{d}^{i}\right)$, where $\hat{d}^{i}=\hat{d}$, are a solution to agent $i$ 's problem given the security price process $\hat{q}$ and the process of agent-specific fees $\hat{p}_{i}^{e}$.

First note that by construction the borrowing constraints are binding for agents with binding ex post incentive compatibility constraints. Also, since $\hat{c}^{i}\left(\omega^{t}\right)>0$ for all $\omega^{t}$ for any optimal allocation, the borrowing constraints are otherwise not binding. Also, given the definition of asset holdings, asset prices and agent-specific prices, for every agent $i$ $\left(\hat{c}^{i}, \hat{a}^{i}, \hat{d}^{i}\right)$ is feasible.

Next, by Lemma 3.4 and the definition of $\hat{q}$, the intertemporal Euler equation given by equation (25) is satisfied since

$$
\frac{\pi_{s} \beta u^{\prime}\left(\hat{c}^{i}\left(\omega^{t}, s\right)\right)}{u^{\prime}\left(\hat{c}^{i}\left(\omega^{t}\right)\right)} \leq \hat{q}\left(\omega^{t}, s\right)
$$

with strict inequality for agents where the ex post incentive compatibility constraint is binding in state $\left(\omega^{t}, s\right)$.

Next, by the definition of $\hat{p}_{i}^{e}$ and the construction of the schedules of borrowing constraints, $\hat{d}^{i}=\hat{d}$ satisfies the first-order necessary condition (26) for every agent $i$ that is borrowing constrained for some state. Also note that unconstrained agents have $\hat{p}_{i}^{e}\left(\omega^{t}\right)=0$ and, hence, are indifferent between any choice of $d^{i}$. We assume that their demand is given by $\hat{d}^{i}=\hat{d}$.

Since the intertemporal Euler equation together with the transversality condition (28) is sufficient for optimality, we are left to check the latter one. If the borrowing constraint is binding for agent $i$ after some history of shocks, $\hat{w}^{i}\left(\omega^{t}\right)-B_{i}\left(\hat{d}^{i}\left(\omega^{t-1}\right), \omega^{t}\right)=0$.

Otherwise, by iterating forward and using the definition of $B_{i}\left(\hat{d}^{i}\left(\omega^{t-1}\right), \omega^{t}\right)$, we have that

$$
\hat{w}^{i}\left(\omega^{t}\right)-B_{i}\left(\hat{d}^{i}\left(\omega^{t-1}\right), \omega^{t}\right)=\sum_{\tau \geq t} \sum_{\omega^{\tau} \in\left(\Omega^{\tau} \mid \omega^{t}\right)} \hat{Q}_{t}\left(\omega^{\tau} \mid \omega^{t}\right) \hat{c}^{i}\left(\omega^{\tau}\right),
$$


where $\hat{Q}_{t}\left(\omega^{t}, \omega^{t}\right) \equiv 1$. Thus,

$$
\begin{aligned}
& \lim _{t \rightarrow \infty} \sum_{\omega^{t} \in\left(\Omega^{t} \mid \omega_{0}\right)} \pi\left(\omega^{t} \mid \omega_{0}\right) \beta^{t} u^{\prime}\left(\hat{c}^{i}\left(\omega^{t}\right)\right)\left[\hat{w}^{i}\left(\omega^{t}\right)-B_{i}\left(\hat{d}^{i}\left(\omega^{t-1}\right), \omega^{t}\right)\right] \\
& \leq \lim _{t \rightarrow \infty} \sum_{\omega^{t} \in\left(\Omega^{t} \mid \omega_{0}\right)} \pi\left(\omega^{t} \mid \omega_{0}\right) \beta^{t} u^{\prime}\left(\hat{c}^{i}\left(\omega^{t}\right)\right) \sum_{\tau \geq t} \sum_{\omega^{\tau} \in\left(\Omega^{\tau} \mid \omega^{t}\right)} \hat{Q}_{t}\left(\omega^{\tau} \mid \omega^{t}\right) \hat{c}^{i}\left(\omega^{\tau}\right) \\
& \leq Y \lim _{t \rightarrow \infty} \sum_{\omega^{t} \in\left(\Omega^{t} \mid \omega_{0}\right)} \pi\left(\omega^{t} \mid \omega_{0}\right) \beta^{t} u^{\prime}\left(\hat{c}^{i}\left(\omega^{t}\right)\right) \sum_{\tau \geq t} \sum_{\omega^{\tau} \in\left(\Omega^{\tau} \mid \omega^{t}\right)} \hat{Q}_{t}\left(\omega^{\tau} \mid \omega^{t}\right) \\
& \leq Y u^{\prime}\left(\hat{c}^{i}\left(\omega_{0}\right)\right) \lim _{t \rightarrow \infty} \sum_{\omega^{t} \in\left(\Omega^{t} \mid \omega_{0}\right)} \hat{Q}_{0}\left(\omega^{t} \mid \omega_{0}\right) \sum_{\tau \geq t} \sum_{\omega^{\tau} \in\left(\Omega^{\tau} \mid \omega_{0}\right)} \hat{Q}_{t}\left(\omega^{\tau} \mid \omega_{0}\right) \\
& \leq Y u^{\prime}\left(\hat{c}^{i}\left(\omega_{0}\right)\right) \lim _{t \rightarrow \infty} \sum_{\tau \geq t} \sum_{\omega^{\tau} \in\left(\Omega^{\tau} \mid \omega_{0}\right)} \hat{Q}_{0}\left(\omega^{\tau} \mid \omega_{0}\right) \\
&=0
\end{aligned}
$$

for all $\omega_{0}$, where we use feasibility, i.e., $\hat{c}^{i}\left(\omega^{t}\right) \leq Y$ for all $\omega^{t}$, the fact that

$$
\hat{Q}_{0}\left(\omega^{t} \mid \omega_{0}\right) \geq \frac{\pi\left(\omega^{t} \mid \omega_{0}\right) \beta^{t} u^{\prime}\left(\hat{c}^{i}\left(\omega^{t}\right)\right)}{u^{\prime}\left(\hat{c}^{i}\left(\omega_{0}\right)\right)}
$$

which follows from iterating on the Euler equation, and, finally, the assumption that implied interest rates are high, which implies that

$$
\lim _{t \rightarrow \infty} \sum_{\tau \geq t} \sum_{\omega^{\tau} \in\left(\Omega^{\tau} \mid \omega_{0}\right)} \hat{Q}_{0}\left(\omega^{\tau} \mid \omega_{0}\right)=0
$$

Hence,

$\lim _{t \rightarrow \infty} E_{0}\left[\beta^{t} \lambda_{t}^{i}\left(w_{t}^{i}-B_{i, t}\left(d^{i}\right)\right)\right]=\sum_{\omega_{0}} \pi\left(\omega_{0}\right)\left(Y u^{\prime}\left(\hat{c}^{i}\left(\omega_{0}\right)\right) \lim _{t \rightarrow \infty} \sum_{\tau \geq t} \sum_{\omega^{\tau} \in\left(\Omega^{\tau} \mid \omega_{0}\right)} \hat{Q}_{0}\left(\omega^{\tau} \mid \omega_{0}\right)\right)=0$

and the transversality condition is fulfilled.

Since markets clear by construction, we are to satisfy the last condition in Definition 3.2 that the borrowing constraints are not too tight. We construct first the functions $\left\{J_{t}^{0}\right\}_{t=0}^{\infty}$ given security price process $\hat{q}$, agent-specific prices $\hat{p}_{i}^{e}$ and the functions for $B_{i}\left(d^{i}\left(\omega^{t}\right),\left(\omega^{t}, s\right)\right)$ we defined earlier. We then adjust the schedules of borrowing constraints and iterate until convergence to condition (22). We distinguish here the two cases of binding and non-binding borrowing constraints. 
Whenever the ex post incentive compatibility constraint for agent $i$ is binding in state $\left(\omega^{t}, s\right), B_{i}\left(\hat{d}^{i}\left(\omega^{t}\right),\left(\omega^{t}, s\right)\right)=\hat{w}^{i}\left(\omega^{t}, s\right)$ and, hence,

$$
\begin{aligned}
J_{t+1}^{0}\left(B_{i}\left(\hat{d}^{i}\left(\omega^{t}\right),\left(\omega^{t}, s\right)\right)\right. & =J_{t+1}^{0}\left(\hat{w}^{i}\left(\omega^{t}, s\right),\left(\omega^{t}, s\right)\right) \\
& =\left(1-\hat{d}\left(\omega^{t}\right)\right)\left[u\left(y_{s}^{i}\right)+\beta V_{\text {aut }}\right] .
\end{aligned}
$$

Since $B_{i}\left(\hat{d}^{i}\left(\omega^{t}\right),\left(\omega^{t}, s\right)\right)$ is linear and strictly decreasing in $d^{i}\left(\omega^{t}\right), J_{t+1}^{0}$ is also a strictly decreasing and strictly concave function of $d^{i}\left(\omega^{t}\right)$ with $B_{i}\left(\hat{d}^{i}\left(\omega^{t}\right),\left(\omega^{t}, s\right)\right.$ being the tangent at $\hat{d}^{i}$. Hence, there exists $\bar{d}^{i}\left(\omega^{t}\right) \in\left(\hat{d}^{i}\left(\omega^{t}\right), 1\right)$ such that

$$
J_{t+1}^{0}\left(B_{i}\left(\bar{d}^{i}\left(\omega^{t}\right),\left(\omega^{t}, s\right)\right)\right)=0 .
$$

This allows us to construct $J_{t+1}^{0}$ for all wealth levels greater than $B_{i}\left(\bar{d}^{i}\left(\omega^{t}\right),\left(\omega^{t}, s\right)\right)$. For wealth levels corresponding to $d^{i}\left(\omega^{t}\right)>\bar{d}^{i}\left(\omega^{t}\right)$ the function $J_{t+1}^{0}\left(B_{i}\left(d^{i}\left(\omega^{t}\right),\left(\omega^{t}, s\right)\right)\right)$ is not defined.

Note that, by the previous claim, $\left(\hat{c}^{i}, \hat{a}^{i}, \hat{d}^{i}\right)$ are solutions to agent $i$ 's problem and, hence, are solutions for $\left\{J_{t}^{0}\right\}_{t=0}^{\infty}$ given initial asset holdings $a_{0}^{i}$ and the choice of $d^{i}\left(\omega^{t}\right)$ being restricted to the interval $\left[0, \bar{d}^{i}\right]$.

Define then a new schedule of borrowing constraints $B_{i}^{1}(\cdot)$ by

$$
J_{t+1}^{0}\left(B_{i}^{1}\left(d^{i}\left(\omega^{t}\right),\left(\omega^{t}, s\right)\right)\right)=\left(1-d^{i}\left(\omega^{t}\right)\right)\left[u\left(y_{s}^{i}\right)+\beta V_{a u t}\right]
$$

for all $d^{i} \in\left[0, \bar{d}^{i}\right]$. Clearly, $B_{i}^{1}(\cdot)$ is a strictly decreasing and strictly convex function on $\left[0, \bar{d}^{i}\right]$ being tangent to $J_{t+1}^{0}$ at $\hat{d}^{i}$. Then, there exists $\bar{d}^{i, 1}\left(\omega^{t}\right)>\bar{d}^{i}$ such that

$$
J_{t+1}^{0}\left(B_{i}^{1}\left(\bar{d}^{i, 1}\left(\omega^{t}\right),\left(\omega^{t}, s\right)\right)\right)=0
$$

For the case where the ex post incentive compatibility constraint is not binding, note that

$$
J_{t+1}^{0}\left(B_{i}\left(\hat{d}^{i}\left(\omega^{t}, s\right),\left(\omega^{t}, s\right)\right)\right)=0<\left(1-\hat{d}\left(\omega^{t}\right)\right)\left[u\left(y_{s}^{i}\right)+\beta V_{a u t}\right]
$$


since $\hat{d}^{i}\left(\omega^{t}\right)<1$ for all $\omega^{t}$ and borrowing up to the net present value of future endowment net of taxes implies that future consumption will be equal to 0. We can then construct the function $J_{t+1}^{0}$ for wealth levels greater than $\left.B_{i}\left(\hat{d}^{i}\left(\omega^{t}, s\right),\left(\omega^{t}, s\right)\right)\right)$. Next, we define new schedules of borrowing constraints and new cut-off levels $\bar{d}^{i}$ as for the other case.

Since $\hat{w}^{i}\left(\omega^{t}, s\right) \geq B_{i}^{1}\left(\left(\hat{d}^{i}\left(\omega^{t}, s\right),\left(\omega^{t}, s\right)\right),\left(\hat{c}^{i}, \hat{a}^{i}, \hat{d}^{i}\right)\right.$ are still feasible given the initial asset holdings and, hence, optimal. We can then construct new functions $\left\{J_{t}^{1}\right\}_{t=0}^{\infty}$ for the price process $\hat{q}$ and $\hat{p}_{i}^{e}$, the new process of borrowing constraints $B_{i}^{1}(\cdot)$ and the new cut-off values for $\bar{d}_{1}^{i}$. Iterating until convergence yields borrowing schedule $\hat{B}_{i}(\cdot)$ and a cut-off value $\bar{d}^{i}=1$ such that

$$
J_{t+1}\left(\hat{B}_{i}\left(d^{i}\left(\omega^{t}\right),\left(\omega^{t}, s\right)\right)\right)=\left(1-d^{i}\left(\omega^{t}\right)\right)\left[u\left(y_{s}^{i}\right)+\beta V_{a u t}\right]
$$

for all $d^{i} \in[0,1]$. This completes the proof.

\section{Proof of Theorem 4.2:}

Proof. Let $\left\{\hat{c}^{i}, \hat{d}^{i}\right\}_{i \in I}$ be a Lindahl-equilibrium. Hence, $\hat{d}^{i}=\hat{d}$ for all $i$. Then, given the borrowing constraints are not too tight, the allocation satisfies the participation constraints (40). Next, define the pricing functional $p_{0}$ by equation (44) and agentspecific prices for every agent $i$ by equation (45).

Given $\left\{\tilde{p}_{i}^{e}\right\}_{i \in I}$, we first show that $\hat{d}$ solves the intermediary's problem. From the definition of the implied Arrow-Debreu prices $q_{0}\left(\omega^{t}, s\right)$ and the fact that the participation constraints are binding if and only if the corresponding borrowing constraints are binding, it follows that $\tilde{p}_{i}^{e}\left(\omega^{t}\right)=\hat{p}_{i}^{e}$ for all $i \in I$ and $\omega^{t}$. Since the first-order necessary conditions for the intermediary's problem are identical to equation (11), $\hat{d}$ maximizes profits. 
Next, the Lagrangian function of agent $i$ is given by

$$
\begin{aligned}
& L\left(c^{i}, d^{i}, \lambda_{0}, \eta^{i}\right)=E_{0}\left[\sum_{t=0}^{\infty} \beta^{t} u\left(c_{t}^{i}\right) \mid \omega_{0}\right]+\lambda_{0}\left[w_{0}^{i}+p_{0}\left(y^{i}+\frac{\Theta}{\# I}\right)-p_{0}\left(c^{i}+\tilde{p}_{i}^{e} d^{i}\right)\right] \\
& +\sum_{t=0}^{\infty} \sum_{\omega^{t} \in \Omega^{t} \mid \omega_{0}} \beta^{t} \pi\left(\omega^{t} \mid \omega_{0}\right) \eta^{i}\left(\omega^{t}\right)\left[u\left(c^{i}\left(\omega^{t-1}, s\right)\right)+E_{t}\left[\sum_{\tau=1}^{\infty} \beta^{\tau} u\left(c_{\tau}^{i}\right)\right]-\left(1-d^{i}\left(\omega^{t-1}\right)\right)\left[u\left(y_{s}^{i}\right)+\right.\right.
\end{aligned}
$$

where $\eta^{i}$ is the process of Lagrange multipliers on the participation constraints of agent $i$. For any given process $c^{i}$ define now $\lambda_{0}$ by

$$
\lambda_{0}=u^{\prime}\left(c^{i}\left(\omega_{0}\right)\right)
$$

Furthermore, let the multipliers $\eta^{i}\left(\omega^{t}, s\right)$ be given recursively by

$$
\beta^{t+1} \pi\left(\left(\omega^{t}, s\right) \mid \omega_{0}\right) u^{\prime}\left(c^{i}\left(\omega^{t}, s\right)\right)\left[1+\sum_{\omega^{\tau} \prec\left(\omega^{t}, s\right)} \frac{\eta^{i}\left(\omega^{\tau}\right)}{\beta^{\tau} \pi\left(\omega^{\tau} \mid \omega_{0}\right)}\right]=\lambda_{0} Q_{0}\left(\left(\omega^{t}, s\right) \mid \omega_{0}\right)
$$

with $\eta^{i}\left(\omega_{0}\right) \equiv 0$. Thus, by construction for any given process $c^{i}$, the Lagrange multipliers minimize the function $L$.

We then verify that - given a choice for $c^{i}$ - the definition of agent specific prices $\tilde{p}_{i}^{e}$ fulfills the first-order necessary condition of $L$ with respect to $d^{i}$. The first-order necessary condition of the Lagrangian $L$ with respect to $d^{i}\left(\omega^{t}\right)$ is given by

$$
\tilde{p}_{i}^{e}\left(\omega^{t}\right)=\frac{\sum_{s \in S}-\eta^{i}\left(\omega^{t}, s\right)\left[u\left(y_{s}^{i}\right)+\beta V_{a u t}\right]}{\lambda_{0} \sum_{s \in S} Q_{0}\left(\left(\omega^{t}, s\right) \mid \omega_{0}\right)} .
$$

From the definition of $q_{0}\left(\omega^{t}, s\right)$ and $\eta^{i}\left(\omega^{t}, s\right)$ we have that

$$
\lambda_{0} Q_{0}\left(\left(\omega^{t}, s\right) \mid \omega_{0}\right)=q_{0}\left(\omega^{t}, s\right) \beta^{t} \pi\left(\omega^{t} \mid \omega_{0}\right) u^{\prime}\left(c^{i}\left(\omega^{t}\right)\right)\left[1+\sum_{\omega^{\tau} \prec \omega^{t}} \tilde{\eta}^{i}\left(\omega^{\tau}\right)\right],
$$

where $\tilde{\eta}^{i}\left(\omega^{t}\right) \equiv \frac{\eta^{i}\left(\omega^{t}\right)}{\beta^{t} \pi\left(\omega^{t} \mid \omega_{0}\right)}$ and

$$
q_{0}\left(\omega^{t}, s\right) u^{\prime}\left(c^{i}\left(\omega^{t}\right)\right)\left[1+\sum_{\omega^{\tau} \prec \omega^{t}} \tilde{\eta}^{i}\left(\omega^{\tau}\right)\right]=\beta \pi_{s} u^{\prime}\left(c^{i}\left(\omega^{t}, s\right)\right)\left[1+\sum_{\omega^{\tau} \prec\left(\omega^{t}, s\right)} \tilde{\eta}^{i}\left(\omega^{\tau}\right)\right] .
$$

Using the last two expression in the first-order necessary condition for $d^{i}\left(\omega^{t}\right)$ confirms that the definition of $\tilde{p}_{i}^{e}$ is consistent with the definition of the Lagrange multipliers. 
From the definition of $\eta^{i}\left(\omega^{t}\right)$ and the assumption that interest rates are high, we have

$$
\begin{aligned}
\sum_{t=0}^{\infty} \sum_{\omega^{t} \in \Omega^{t} \mid \omega_{0}} \beta^{t} \pi\left(\omega^{t} \mid \omega_{0}\right) \eta^{i}\left(\omega^{t}\right) & {\left[u\left(c^{i}\left(\omega^{t-1}, s\right)\right)+E_{t}\left[\sum_{\tau=1}^{\infty} \beta^{\tau} u\left(c_{\tau}^{i}\right)\right]\right]=} \\
& =\sum_{t=0}^{\infty} \sum_{\omega^{t} \in \Omega^{t} \mid \omega_{0}} \lambda_{0} Q_{0}\left(\omega^{t} \mid \omega_{0}\right) \frac{u\left(c^{i}\left(\omega^{t}\right)\right)}{u^{\prime}\left(c^{i}\left(\omega^{t}\right)\right)} \\
& \leq \lambda_{0} \sum_{t=0}^{\infty} \sum_{\omega^{t} \in \Omega^{t} \mid \omega_{0}} Q_{0}\left(\omega^{t} \mid \omega_{0}\right) c^{i}\left(\omega^{t}\right) \\
& <\infty
\end{aligned}
$$

where the weak inequality follows from the concavity of $u$ and the fact that $u$ is bounded below. Furthermore,

$$
\begin{aligned}
\sum_{t=0}^{\infty} \sum_{\omega^{t} \in \Omega^{t} \mid \omega_{0}} & \beta^{t} \pi\left(\omega^{t} \mid \omega_{0}\right) \eta^{i}\left(\omega^{t}\right)\left(1-d^{i}\left(\omega^{t-1}\right)\right)\left[u\left(y_{s}^{i}\right)+\beta V_{a u t}\right] \leq \\
& \leq \sum_{t=0}^{\infty} \sum_{\omega^{t} \in \Omega^{t} \mid \omega_{0}} \beta^{t} \pi\left(\omega^{t} \mid \omega_{0}\right) \eta^{i}\left(\omega^{t}\right)\left[u\left(c^{i}\left(\omega^{t-1}, s\right)\right)+E_{t}\left[\sum_{\tau=1}^{\infty} \beta^{\tau} u\left(c_{\tau}^{i}\right)\right]\right] \\
& <\infty
\end{aligned}
$$

and all other terms of the Lagrangian $L$ are finite which allows us to exchange the order of summation in the definition of the Lagrangian $L$.

This allows us to prove that $\left(\hat{c}^{i}, \hat{d}^{i}\right)$ are optimal given the definitions of prices and multipliers. Dropping constant terms from the Lagrangian, using the definition of $p_{0}$ and $\tilde{p}_{i}^{e}$ 
as well as collecting terms we obtain

$$
\begin{aligned}
& \sum_{t=0}^{\infty} \sum_{\omega^{t} \in \Omega^{t} \mid \omega_{0}}\left(\beta^{t} \pi\left(\omega^{t} \mid \omega_{0}\right) u\left(c^{i}\left(\omega^{t}\right)\right)\left[1+\sum_{\omega^{\tau} \prec \omega^{t}} \tilde{\eta}^{i}\left(\omega^{\tau}\right)\right]-\lambda_{0} Q_{0}\left(\omega^{t} \mid \omega_{0}\right)\left(c^{i}\left(\omega^{t}\right)+\tilde{p}_{i}^{e}\left(\omega^{t-1}\right) d^{i}\left(\omega^{t-1}\right)\right.\right. \\
& \left.\quad+\eta^{i}\left(\omega^{t-1}, s\right) d^{i}\left(\omega^{t-1}\right)\left[u\left(y_{s}^{i}\right)+\beta V_{a u t}\right]\right)= \\
& \sum_{t=0}^{\infty} \sum_{\omega^{t} \in \Omega^{t} \mid \omega_{0}}\left(\beta^{t} \pi\left(\omega^{t} \mid \omega_{0}\right) u\left(c^{i}\left(\omega^{t}\right)\right)\left[1+\sum_{\omega^{\tau} \prec \omega^{t}} \tilde{\eta}^{i}\left(\omega^{\tau}\right)\right]-\lambda_{0} Q_{0}\left(\omega^{t} \mid \omega_{0}\right) c^{i}\left(\omega^{t}\right)\right)- \\
& \quad-\sum_{t=0}^{\infty} \sum_{\omega^{t} \in \Omega^{t} \mid \omega_{0}} d^{i}\left(\omega^{t-1}\right)\left(\eta^{i}\left(\omega^{t-1}, s\right)\left[u\left(y_{s}^{i}\right)+\beta V_{a u t}\right]-\lambda_{0} Q_{0}\left(\left(\omega^{t-1}, s\right) \mid \omega_{0}\right) \tilde{p}_{i}^{e}\left(\omega^{t-1}\right)\right)= \\
& \sum_{t=0}^{\infty} \sum_{\omega^{t} \in \Omega^{t} \mid \omega_{0}}\left(\beta^{t} \pi\left(\omega^{t} \mid \omega_{0}\right) u\left(c^{i}\left(\omega^{t}\right)\right)\left[1+\sum_{\omega^{\tau} \prec \omega^{t}} \tilde{\eta}^{i}\left(\omega^{\tau}\right)\right]-\lambda_{0} Q_{0}\left(\omega^{t} \mid \omega_{0}\right) c^{i}\left(\omega^{t}\right)\right)- \\
& \quad-\sum_{t=0}^{\infty} \sum_{\omega^{t-1} \in \Omega^{t-1} \mid \omega_{0}} d^{i}\left(\omega^{t-1}\right) \sum_{s \in S}\left(\eta^{i}\left(\omega^{t-1}, s\right)\left[u\left(y_{s}^{i}\right)+\beta V_{a u t}\right]-\lambda_{0} Q_{0}\left(\left(\omega^{t-1}, s\right) \mid \omega_{0}\right) \tilde{p}_{i}^{e}\left(\omega^{t-1}\right)\right)= \\
& \sum_{t=0}^{\infty} \sum_{\omega^{t} \in \Omega^{t} \mid \omega_{0}}\left(\beta^{t} \pi\left(\omega^{t} \mid \omega_{0}\right) u\left(c^{i}\left(\omega^{t}\right)\right)\left[1+\sum_{\omega^{\tau} \prec \omega^{t}} \tilde{\eta}^{i}\left(\omega^{\tau}\right)\right]-\lambda_{0} Q_{0}\left(\omega^{t} \mid \omega_{0}\right) c^{i}\left(\omega^{t}\right)\right) .
\end{aligned}
$$

Finally, using the fact that $u^{\prime}\left(\hat{c}^{i}\left(\omega^{t}\right)\right) \geq \frac{u\left(c^{i}\left(\omega^{t}\right)\right)-u\left(\hat{c}^{i}\left(\omega^{t}\right)\right)}{c^{i}\left(\omega^{t}\right)-\hat{c}^{i}\left(\omega^{t}\right)}$, which follows from the concavity of $u$, and the definition of the multipliers $\eta^{i}$, the optimality of $\left(\hat{c}^{i}, \hat{d}^{i}\right)$ follows since

$$
\begin{aligned}
& \sum_{t=0}^{\infty} \sum_{\omega^{t} \in \Omega^{t} \mid \omega_{0}}\left(\beta^{t} \pi\left(\omega^{t} \mid \omega_{0}\right) u\left(c^{i}\left(\omega^{t}\right)\right)\left[1+\sum_{\omega^{\tau} \prec \omega^{t}} \tilde{\eta}^{i}\left(\omega^{\tau}\right)\right]-\lambda_{0} Q_{0}\left(\omega^{t} \mid \omega_{0}\right) c^{i}\left(\omega^{t}\right)\right) \leq \\
& \sum_{t=0}^{\infty} \sum_{\omega^{t} \in \Omega^{t} \mid \omega_{0}} \beta^{t} \pi\left(\omega^{t} \mid \omega_{0}\right)\left[u\left(\hat{c}^{i}\left(\omega^{t}\right)+u^{\prime}\left(\hat{c}^{i}\left(\omega^{t}\right)\right)\left[c^{i}\left(\omega^{t}\right)-\hat{c}^{i}\left(\omega^{t}\right)\right]\right]\left[1+\sum_{\omega^{\tau} \prec \omega^{t}} \tilde{\eta}^{i}\left(\omega^{\tau}\right)\right]-\right. \\
& \quad-\lambda_{0} \sum_{t=0}^{\infty} \sum_{\omega^{t} \in \Omega^{t} \mid \omega_{0}} Q_{0}\left(\omega^{t} \mid \omega_{0}\right) c^{i}\left(\omega^{t}\right)= \\
& \sum_{t=0}^{\infty} \sum_{\omega^{t} \in \Omega^{t} \mid \omega_{0}} \beta^{t} \pi\left(\omega^{t} \mid \omega_{0}\right) u\left(\hat{c}^{i}\left(\omega^{t}\right)\right)\left[1+\sum_{\omega^{\tau} \prec \omega^{t}} \tilde{\eta}^{i}\left(\omega^{\tau}\right)\right]-\lambda_{0} \sum_{t=0}^{\infty} \sum_{\omega^{t} \in \Omega^{t} \mid \omega_{0}} Q_{0}\left(\omega^{t} \mid \omega_{0}\right) \hat{c}^{i}\left(\omega^{t}\right) .
\end{aligned}
$$




\section{Proof of Proposition 5.1:}

Proof. Suppose $\hat{d}\left(\omega^{t-1}\right) \leq \hat{d}\left(\omega^{t}\right)$. Then, from resource feasibility it follows for all $s \in S$ that $\sum_{i \in I} \hat{c}^{i}\left(\omega^{t}\right) \geq \sum_{i \in I} \hat{c}^{i}\left(\omega^{t}, s\right)$. Hence, for all $s \in S$, there exists $j \in I$ with $\frac{u^{\prime}\left(\hat{c}^{j}\left(\omega^{t}, s\right)\right)}{u^{\prime}\left(\hat{c}^{j}\left(\omega^{t}\right)\right)} \geq$ 1. From equation (33) it follows immediately that

$$
q\left(\omega^{t}, s\right) \geq \beta \pi_{s} \frac{u^{\prime}\left(\hat{c}^{j}\left(\omega^{t}, s\right)\right)}{u^{\prime}\left(\hat{c}^{j}\left(\omega^{t}\right)\right)} \geq \beta \pi_{s} .
$$

The second part of the proof follows directly from summing equation (33) over $s \in S$. 


\section{References}

Alvarez, F., Jermann, U. (2000). Efficiency, Equilibrium, and Asset Pricing with Risk of Default. Econometrica 68, 775-797.

Bisin, A., Gottardi, P. (2000). Efficient Competitive Equilibria with Adverse Selection. Manuscript, New York University.

Chatterjee, S., Corbae, D., Nakajima, M., Rios-Rull, J. (2002). A Quantitative Theory of Unsecured Consumer Credit with Risk of Default. Manuscript, University of Pennsylvania.

Coate, S., Ravallion, M. (1993). Reciprocity without commitment: Characterization and Performance of Informal Insurance Arrangements. Journal of Development Economics 40, 1-24.

Constantinides, G., Duffie, D. (1996). Asset Pricing with Heterogeneous Consumers. Journal of Political Economy 104, 219-240.

Green, Edward (2000). Clearing and Settling Financial Transactions. Manuscript, Federal Reserve Bank of Chicago.

He, H., Modest, M. (1995). Market Frictions and Consumption-Based Asset Pricing. Journal of Political Economy 103, 94-117.

Kehoe, T., Levine, D. (1993). Debt-Constrained Asset Markets. Review of Economic Studies 60, 865-888.

Kocherlakota, N. (1996). Implications of Efficient Risk sharing without Commitment. Review of Economic Studies 63, 595-609.

Koeppl, T. (2002). Risk Sharing with Endogenous Enforcement - A Contract Theoretic Perspective. Unpublished PhD-Thesis, University of Minnesota.

Koeppl, T. (2003). Optimal Dynamic Risk Sharing when Enforcement is a Decision Variable, ECB Working Paper 282.

Levine, D., Zame, W. (1996). Debt-Constraints and Equilibrium in Infinite Horizon Economies with Incomplete Markets. Journal of Mathematical Economics 26, 103-131.

Lindahl, E. (1919). Die Gerechtigkeit der Besteuerung, Lund, Gleerup.

Livshits, I., MacGee, J., Tertilt, M. (2001). Consumer Bankruptcy: A Fresh Start. Federal Reserve Bank of Minneapolis, Working Paper 617.

Luttmer, E. (1996). Asset Pricing in Economies with Frictions. Econometrica 64, 14391467.

Malinvaud, E. (1972). Lectures on Microeconomic Theory, North-Holland, Amsterdam

Milleron, J. (1972). Theory of Value with Public Goods: A Survey Article. Journal of Economic Theory 5, 419-477.

Samuelson, P. (1954). The Pure Theory Public Expenditure. Review of Economics and Statistics 36, 387-389.

Zhang, H. (1997), Endogenous Borrowing Constraints with Incomplete Markets. Journal of Finance 52, 2187-2205. 


\section{European Central Bank working paper series}

For a complete list of Working Papers published by the ECB, please visit the ECB's website (http://www.ecb.int).

202 "Aggregate loans to the euro area private sector" by A. Calza, M. Manrique and J. Sousa, January 2003.

203 "Myopic loss aversion, disappointment aversion and the equity premium puzzle" by D. Fielding and L. Stracca, January 2003.

204 "Asymmetric dynamics in the correlations of global equity and bond returns" by L. Cappiello, R.F. Engle and K. Sheppard, January 2003.

205 "Real exchange rate in an inter-temporal n-country-model with incomplete markets" by B. Mercereau, January 2003.

206 "Empirical estimates of reaction functions for the euro area" by D. Gerdesmeier and B. Roffia, January 2003.

207 “A comprehensive model on the euro overnight rate” by F. R. Würtz, January 2003.

208 "Do demographic changes affect risk premiums? Evidence from international data" by A. Ang and A. Maddaloni, January 2003.

209 "A framework for collateral risk control determination" by D. Cossin, Z. Huang, D. Aunon-Nerin and F. González, January 2003.

210 "Anticipated Ramsey reforms and the uniform taxation principle: the role of international financial markets” by S. Schmitt-Grohé and M. Uribe, January 2003.

2II “Self-control and savings" by P. Michel and J.P. Vidal, January 2003.

212 "Modelling the implied probability of stock market movements" by E. Glatzer and M. Scheicher, January 2003.

213 “Aggregation and euro area Phillips curves” by S. Fabiani and J. Morgan, February 2003.

2I4 “On the selection of forecasting models" by A. Inoue and L. Kilian, February 2003.

215 "Budget institutions and fiscal performance in Central and Eastern European countries" by H. Gleich, February 2003.

216 "The admission of accession countries to an enlarged monetary union: a tentative assessment” by M. Ca'Zorzi and R. A. De Santis, February 2003.

217 "The role of product market regulations in the process of structural change" by J. Messina, March 2003. 
218 "The zero-interest-rate bound and the role of the exchange rate for monetary policy in Japan" by G. Coenen and V. Wieland, March 2003.

219 "Extra-euro area manufacturing import prices and exchange rate pass-through" by B. Anderton, March 2003.

220 "The allocation of competencies in an international union: a positive analysis" by M. Ruta, April 2003.

221 "Estimating risk premia in money market rates" by A. Durré, S. Evjen and R. Pilegaard, April 2003.

222 "Inflation dynamics and subjective expectations in the United States" by K. Adam and M. Padula, April 2003.

223 "Optimal monetary policy with imperfect common knowledge" by K. Adam, April 2003.

224 "The rise of the yen vis-à-vis the ("synthetic") euro: is it supported by economic fundamentals?" by C. Osbat, R. Rüffer and B. Schnatz, April 2003.

225 "Productivity and the ("synthetic") euro-dollar exchange rate" by C. Osbat, F. Vijselaar and B. Schnatz, April 2003.

226 "The central banker as a risk manager: quantifying and forecasting inflation risks" by L. Kilian and S. Manganelli, April 2003.

227 "Monetary policy in a low pass-through environment" by T. Monacelli, April 2003.

228 "Monetary policy shocks - a nonfundamental look at the data" by M. Klaeffing, May 2003.

229 “How does the ECB target inflation?" by P. Surico, May 2003.

230 "The euro area financial system: structure, integration and policy initiatives" by P. Hartmann, A. Maddaloni and S. Manganelli, May 2003.

23I "Price stability and monetary policy effectiveness when nominal interest rates are bounded at zero" by G. Coenen, A. Orphanides and V. Wieland, May 2003.

232 "Describing the Fed's conduct with Taylor rules: is interest rate smoothing important?" by E. Castelnuovo, May 2003.

233 "The natural real rate of interest in the euro area" by N. Giammarioli and N. Valla, May 2003.

234 "Unemployment, hysteresis and transition" by M. León-Ledesma and P. McAdam, May 2003.

235 "Volatility of interest rates in the euro area: evidence from high frequency data" by N. Cassola and C. Morana, June 2003. 
236 "Swiss monetary targeting 1974-1996: the role of internal policy analysis" by G. Rich, June 2003.

237 "Growth expectations, capital flows and international risk sharing" by O. Castrén, M. Miller and R. Stiegert, June 2003.

238 "The impact of monetary union on trade prices" by R. Anderton, R. E. Baldwin and D. Taglioni, June 2003.

239 "Temporary shocks and unavoidable transitions to a high-unemployment regime" by W. J. Denhaan, June 2003.

240 "Monetary policy transmission in the euro area: any changes after EMU?" by I. Angeloni and M. Ehrmann, July 2003.

24I Maintaining price stability under free-floating: a fearless way out of the corner?" by C. Detken and V. Gaspar, July 2003.

242 "Public sector efficiency: an international comparison" by A. Afonso, L. Schuknecht and V. Tanzi, July 2003.

243 “Pass-through of external shocks to euro area inflation” by E. Hahn, July 2003.

244 "How does the ECB allot liquidity in its weekly main refinancing operations? A look at the empirical evidence" by S. Ejerskov, C. Martin Moss and L. Stracca, July 2003.

245 "Money and payments: a modern perspective" by C. Holthausen and C. Monnet, July 2003.

246 "Public finances and long-term growth in Europe - evidence from a panel data analysis" by D. R. de Ávila Torrijos and R. Strauch, July 2003.

247 "Forecasting euro area inflation: does aggregating forecasts by HICP component improve forecast accuracy?" by K. Hubrich, August 2003.

248 "Exchange rates and fundamentals" by C. Engel and K. D. West, August 2003.

249 "Trade advantages and specialisation dynamics in acceding countries" by A. Zaghini, August 2003.

250 "Persistence, the transmission mechanism and robust monetary policy" by I. Angeloni, G. Coenen and F. Smets, August 2003.

25I "Consumption, habit persistence, imperfect information and the lifetime budget constraint" by A. Willman, August 2003.

252 "Interpolation and backdating with a large information set" by E. Angelini, J. Henry and M. Marcellino, August 2003.

253 "Bond market inflation expectations and longer-term trends in broad monetary growth and inflation in industrial countries, 1880-200I” by W. G. Dewald, September 2003. 
254 "Forecasting real GDP: what role for narrow money?" by C. Brand, H.-E. Reimers and F. Seitz, September 2003.

255 "Is the demand for euro area M3 stable?" by A. Bruggeman, P. Donati and A. Warne, September 2003.

256 "Information acquisition and decision making in committees: a survey" by K. Gerling, H. P. Grüner, A. Kiel and E. Schulte, September 2003.

257 "Macroeconomic modelling of monetary policy" by M. Klaeffling, September 2003.

258 "Interest rate reaction functions and the Taylor rule in the euro area" by P. GerlachKristen, September 2003.

259 "Implicit tax co-ordination under repeated policy interactions" by M. Catenaro and J.-P. Vidal, September 2003.

260 "Aggregation-theoretic monetary aggregation over the euro area, when countries are heterogeneous" by W. A. Barnett, September 2003.

261 "Why has broad money demand been more stable in the euro area than in other economies? A literature review" by A. Calza and J. Sousa, September 2003.

262 "Indeterminacy of rational expectations equilibria in sequential financial markets" by P. Donati, September 2003.

263 "Measuring contagion with a Bayesian, time-varying coefficient model" by M. Ciccarelli and A. Rebucci, September 2003.

264 "A monthly monetary model with banking intermediation for the euro area" by A. Bruggeman and M. Donnay, September 2003.

265 "New Keynesian Phillips Curves: a reassessment using euro area data" by P. McAdam and A. Willman, September 2003.

266 "Finance and growth in the EU: new evidence from the liberalisation and harmonisation of the banking industry" by D. Romero de Ávila, September 2003.

267 "Comparing economic dynamics in the EU and CEE accession countries" by R. Süppel, September 2003.

268 "The output composition puzzle: a difference in the monetary transmission mechanism in the euro area and the US" by I. Angeloni, A. K. Kashyap, B. Mojon and D. Terlizzese, September 2003.

269 "Zero lower bound: is it a problem with the euro area?" by G. Coenen, September 2003.

270 "Downward nominal wage rigidity and the long-run Phillips curve: simulation-based evidence for the euro area" by G. Coenen, September 2003.

27I "Indeterminacy and search theory" by N. Giammarioli, September 2003. 
272 "Inflation targets and the liquidity trap" by M. Klaeffling and V. López Pérez, September 2003.

273 "Definition of price stability, range and point inflation targets: the anchoring of long-term inflation expectations” by E. Castelnuovo, S. Nicoletti-Altimari and D. RodriguezPalenzuela, September 2003.

274 "Interpreting implied risk neutral densities: the role of risk premia" by P. Hördahl and D. Vestin, September 2003.

275 "Identifying the monetary transmission mechanism using structural breaks" by A. Beyer and R. Farmer, September 2003.

276 "Short-term estimates of euro area real GDP by means of monthly data" by G. Rünstler, September 2003.

277 "On the indeterminacy of determinacy and indeterminacy" by A. Beyer and R. Farmer, September 2003.

278 "Relevant economic issues concerning the optimal rate of inflation" by D. R. Palenzuela, G. Camba-Méndez and J. Á. García, September 2003.

279 "Designing targeting rules for international monetary policy cooperation" by G. Benigno and P. Benigno, October 2003.

280 “Inflation, factor substitution and growth" by R. Klump, October 2003.

28I "Identifying fiscal shocks and policy regimes in OECD countries" by G. de Arcangelis and S. Lamartina, October 2003.

282 "Optimal dynamic risk sharing when enforcement is a decision variable" by T. V. Koeppl, October 2003.

283 "US, Japan and the euro area: comparing business-cycle features” by P. McAdam, November 2003.

284 "The credibility of the monetary policy 'free lunch"' by J. Yetman, November 2003.

285 "Government deficits, wealth effects and the price level in an optimizing model" by B. Annicchiarico, November 2003.

286 "Country and sector-specific spillover effects in the euro area, the United States and Japan" by B. Kaltenhaeuser, November 2003.

287 “Consumer inflation expectations in Poland” by T. Łyziak, November 2003.

288 "Implementing optimal control cointegrated I(I) structural VAR models" by F. V. Monti, November 2003.

289 "Monetary and fiscal interactions in open economies" by G. Lombardo and A. Sutherland, November 2003. 
290 "Inflation persistence and robust monetary policy design" by G. Coenen, November 2003.

291 "Measuring the time-inconsitency of US monetary policy" by P. Surico, November 2003.

292 "Bank mergers, competition and liquidity" by E. Carletti, P. Hartmann and G. Spagnolo, November 2003.

293 “Committees and special interests” by M. Felgenhauer and H. P. Grüner, November 2003.

294 "Does the yield spread predict recessions in the euro area?" by F. Moneta, December 2003.

295 "Optimal allotment policy in the eurosystem's main refinancing operations?" by C. Ewerhart, N. Cassola, S. Ejerskov and N. Valla, December 2003.

296 "Monetary policy analysis in a small open economy using bayesian cointegrated structural VARs?" by M. Villani and A. Warne, December 2003.

297 “Measurement of contagion in banks' equity prices” by R. Gropp and G. Moerman, December 2003.

298 "The lender of last resort: a 2 I st century approach" by X. Freixas, B. M. Parigi and J.-C. Rochet, December 2003.

299 "Import prices and pricing-to-market effects in the euro area” by T. Warmedinger, January 2004.

300 "Developing statistical indicators of the integration of the euro area banking system" by M. Manna, January 2004.

301 “Inflation and relative price asymmetry” by A. Rátfai, January 2004.

302 “Deposit insurance, moral hazard and market monitoring” by R. Gropp and J. Vesala, February 2004.

303 "Fiscal policy events and interest rate swap spreads: evidence from the EU" by A. Afonso and R. Strauch, February 2004.

304 "Equilibrium unemployment, job flows and inflation dynamics" by A. Trigari, February 2004.

305 “A structural common factor approach to core inflation estimation and forecasting" by C. Morana, February 2004.

306 "A markup model of inflation for the euro area" by C. Bowdler and E. S. Jansen, February 2004.

307 "Budgetary forecasts in Europe - the track record of stability and convergence programmes" by R. Strauch, M. Hallerberg and J. von Hagen, February 2004.

308 "International risk-sharing and the transmission of productivity shocks" by G. Corsetti, L. Dedola and S. Leduc, February 2004.

309 "Monetary policy shocks in the euro area and global liquidity spillovers" by J. Sousa and A. Zaghini, February 2004.

310 "International equity flows and returns: A quantitative equilibrium approach" by R. Albuquerque, G. H. Bauer and M. Schneider, February 2004.

311 "Current account dynamics in OECD and EU acceding countries - an intertemporal approach" by M. Bussière, M. Fratzscher and G. Müller, February 2004. 
312 "Similarities and convergence in G-7 cycles" by F. Canova, M. Ciccarelli and E. Ortega, February 2004.

313 "The high-yield segment of the corporate bond market: a diffusion modelling approach for the United States, the United Kingdom and the euro area" by G. de Bondt and D. Marqués, February 2004.

314 "Exchange rate risks and asset prices in a small open economy" by A. Derviz, March 2004.

315 "Option-implied asymmetries in bond market expectations around money policy actions of the ECB" by S. Vähämaa, March 2004.

316 "Cooperation in international banking supervision" by C. Holthausen and T. Rønde, March 2004.

317 "Fiscal policy and inflation volatility" by P. C. Rother, March 2004.

318 "Gross job flows and institutions in Europe" by R. Gómez-Salvador, J. Messina and G. Vallanti, March 2004.

319 "Risk sharing through financial markets with endogenous enforcement of trades" by T. V. Köppl, March 2004. 
